\title{
PLAN NACIONAL DE PREVENCIÓN Y CONTROL DEL TABAQUISMO
}

Isabel Saiz Martínez-Acitores (1), Jesús Rubio Colavida (1), Isabel Espiga López (1), Begoña Alonso de la Iglesia (2), Javier Blanco Aguilar (3), Mercedes Cortés Mancha (4), José Domingo Cabrera Ortega (5), Pepa Pont Martínez (6), José María Saavedra Rodríguez (7), Javier Toledo Pallarés (8)

(1) Ministerio de Sanidad y Consumo

(2) Comunidad Autónoma de Galicia

(3) Comunidad Autónoma de Andalucía

(4) Comunidad Autónoma de Extremadura

(5) Comunidad Foral de Navarra

(6) Comunidad Valenciana

(7) Comunidad Autónoma de Canarias

(8) Comunidad Autónoma de Aragón

\section{INTRODUCCIÓN}

El consumo de tabaco, fundamentalmente en forma de cigarrillos, se encuentra incorporado en los hábitos de conducta de nuestra sociedad de forma extensa desde los años treinta, coincidiendo con la expansión de la fabricación industrial del cigarrillo y su transformación en una rentable industria.

En España, según los datos de la última Encuesta Nacional de Salud de 2001 (ENSE 2001) la prevalencia del consumo de tabaco en la población de 16 y más años es del $34,4 \%$, lo que representa un ligero descenso respecto a la prevalencia de 1987 (ENSE 1987) que fue del $38,4 \%$. Sin embargo, España es uno de los países de la Unión Europea que presenta una mayor prevalencia de consumo, tanto en hombres como en mujeres. (figura 1).

Paralelamente a la generalización del consumo de tabaco empezaron a aparecer las primeras pruebas sobre su nocividad. El estudio epidemiológico de Doll y Hill en los años cincuenta, en el que se evidenció la relación entre el consumo de tabaco y el exceso de mortalidad, marcó el principio de una extensa lista de nuevos informes en los que se ha relacionado al tabaco como factor de riesgo de un gran número de problemas de salud.

En los países industrializados, el tabaquismo se ha convertido en la primera causa de morbi-mortalidad evitable.

En España, en el año 1998, la mortalidad atribuible al tabaco se estimó en un $16 \%$ de la mortalidad total. Esto, junto al alto coste sanitario y social, unido al hecho de que el tabaquismo es un factor de riesgo susceptible de prevención, ha convertido a «la reducción de la prevalencia de consumo del tabaco» en uno de los objetivos prioritarios de las políticas de salud de cualquier país de nuestro entorno socioeconómico.

El tabaquismo, considerado durante años un hábito, es en realidad una dependencia. La nicotina, el principio activo del tabaco es una droga adictiva y como tal tiene las características de otras drogas: tolerancia, dependencia física y psicológica.

La dependencia del tabaco está reconocida como un trastorno mental y del comportamiento tanto en la Clasificación Internacional de Enfermedades de la Organización Mundial de la Salud (ICD-10) como en el Manual de Diagnóstico y Estadísticas de la Asociación Americana de Psiquiatría (DSM- IV). 


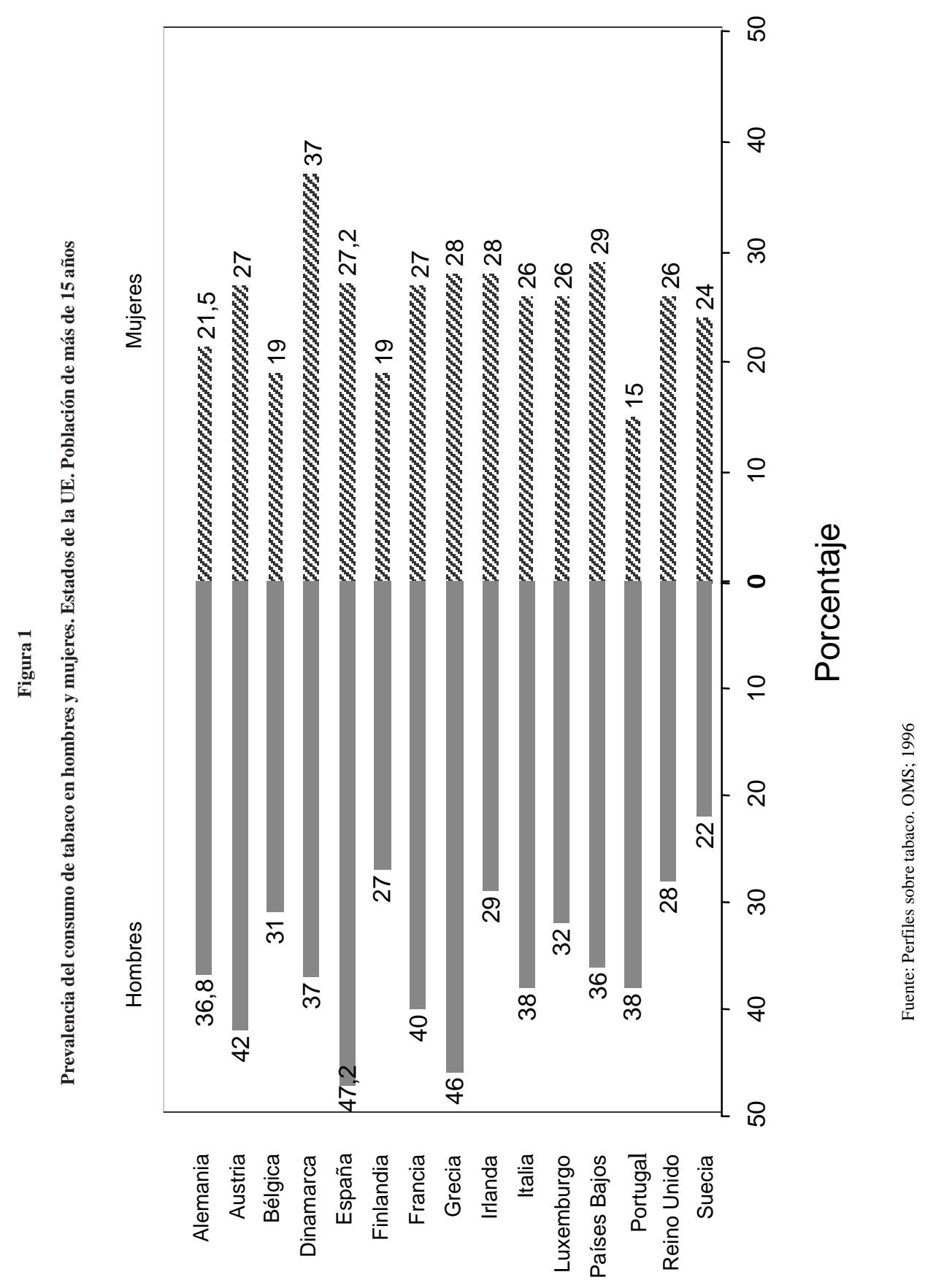




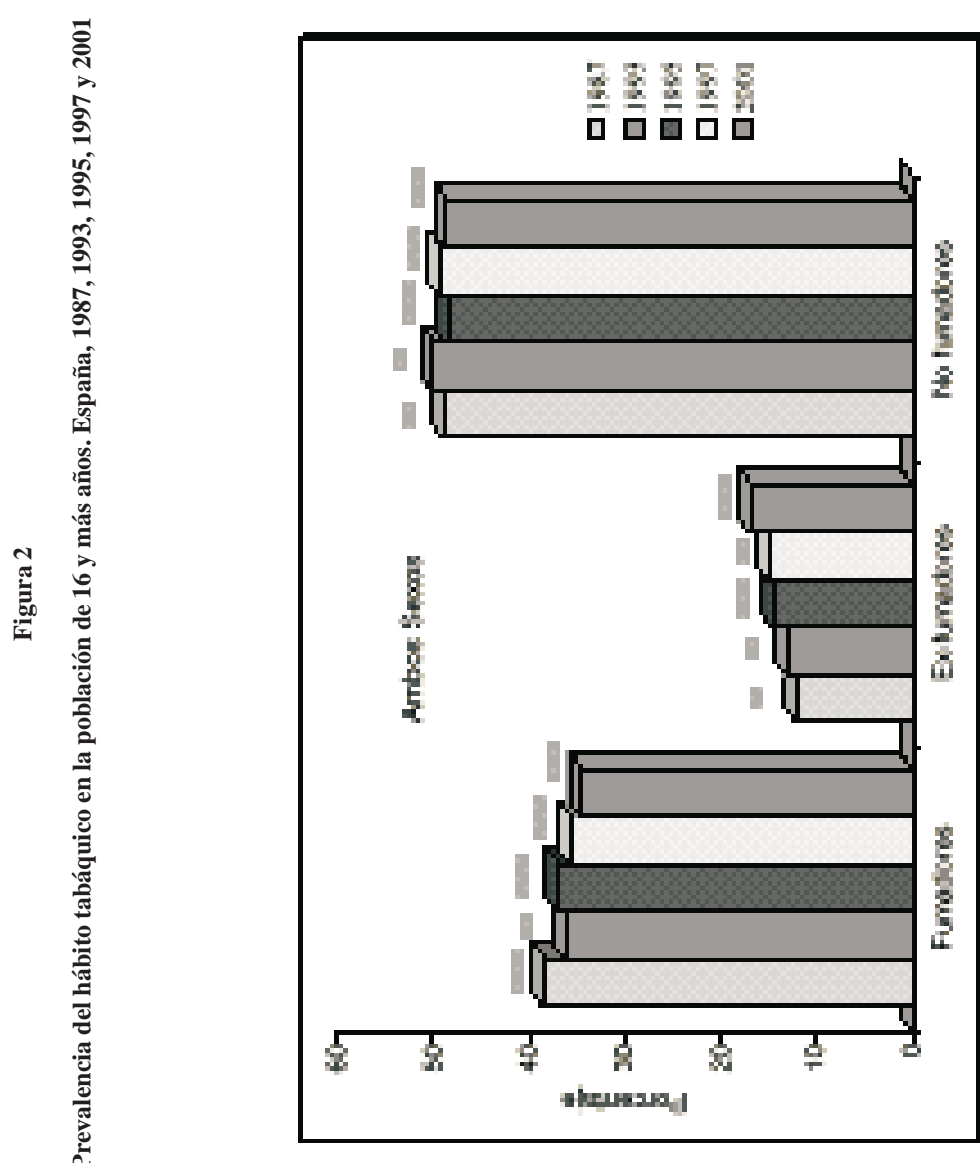




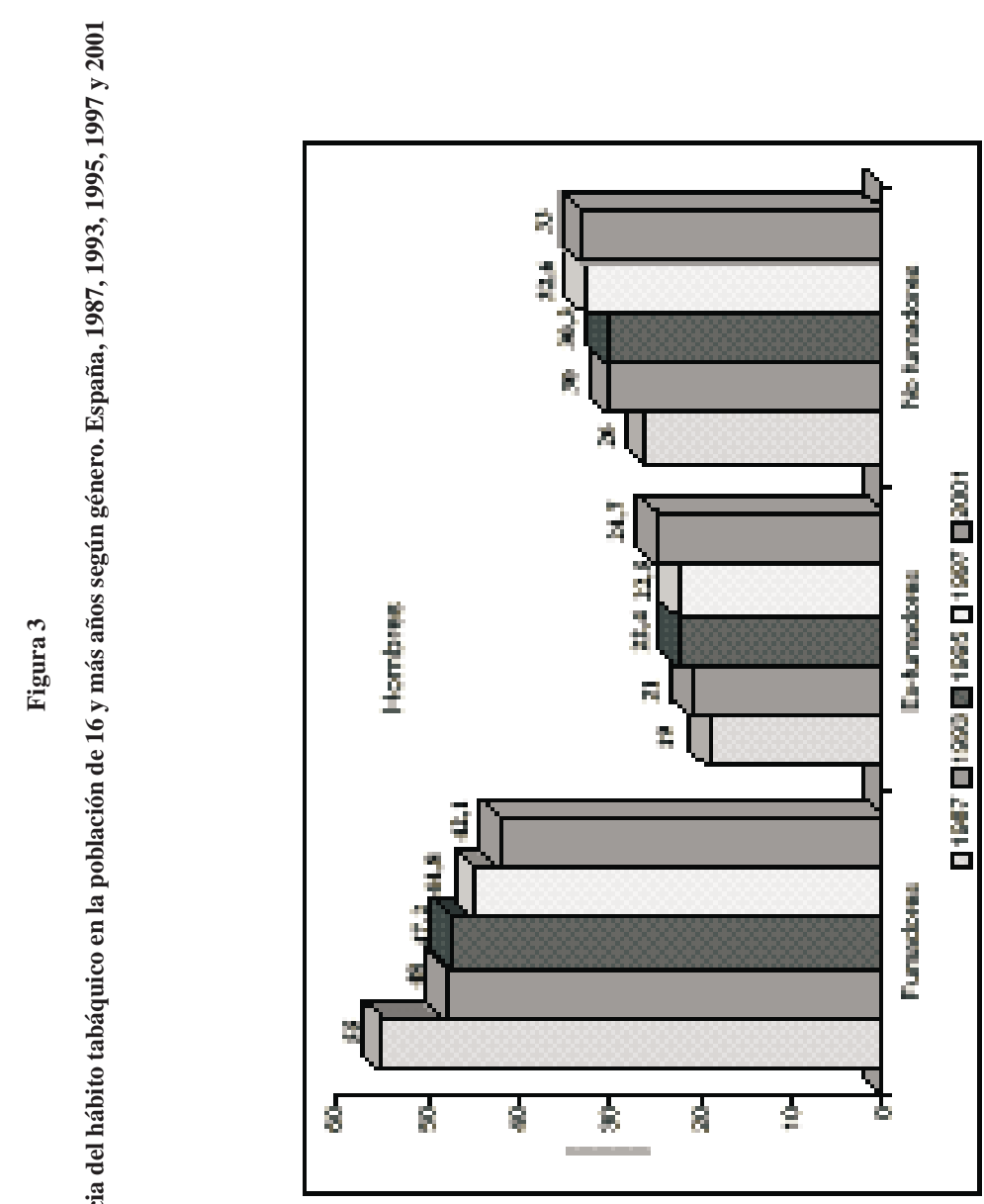

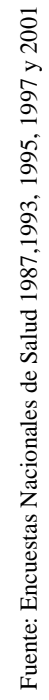




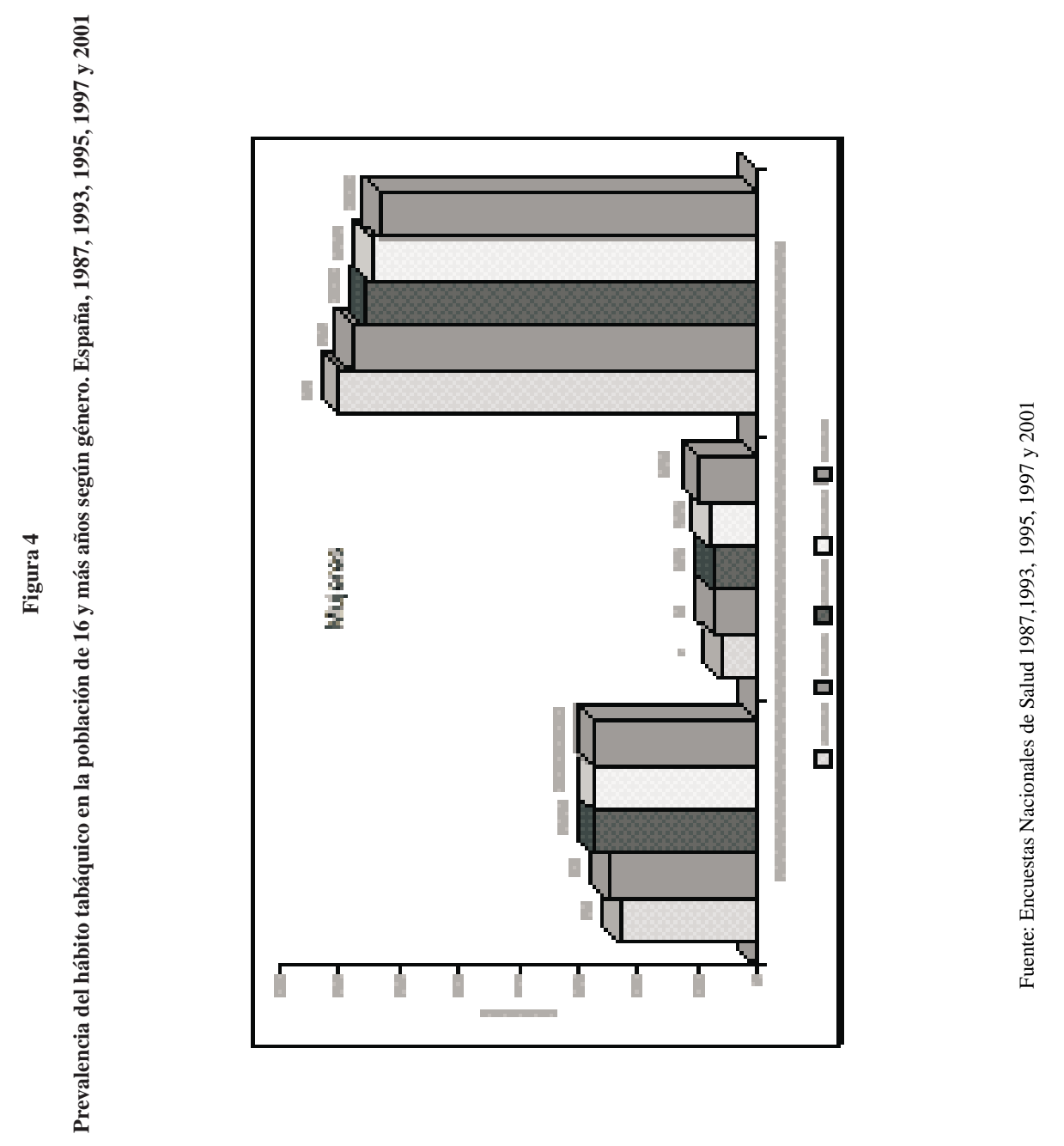




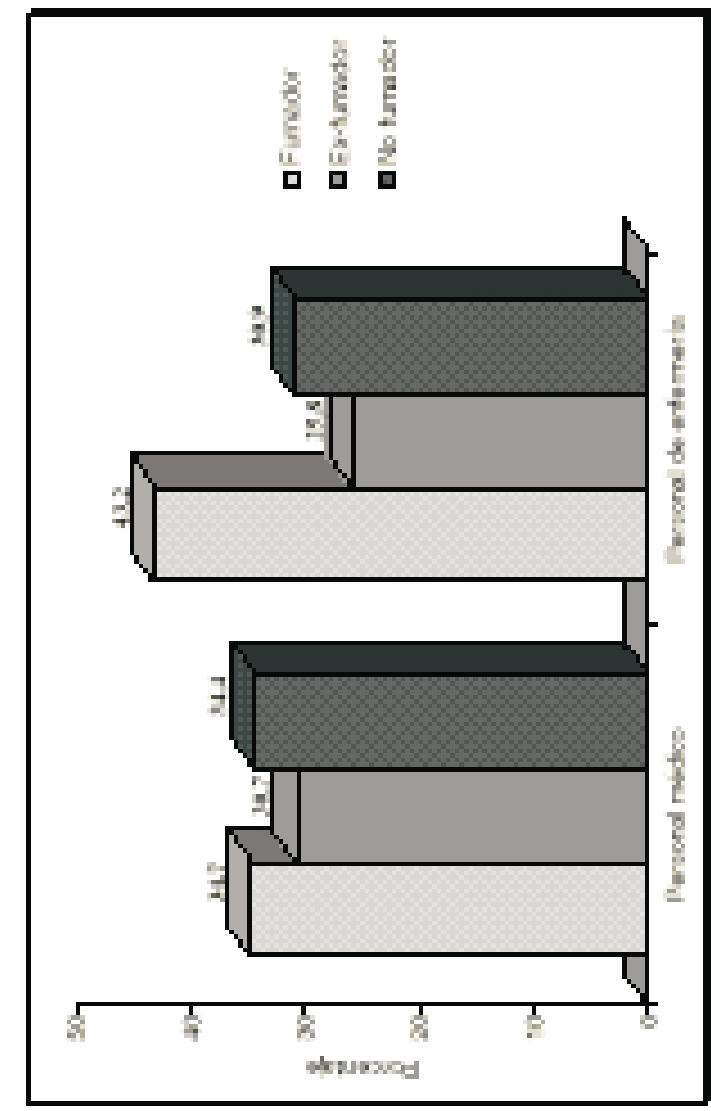




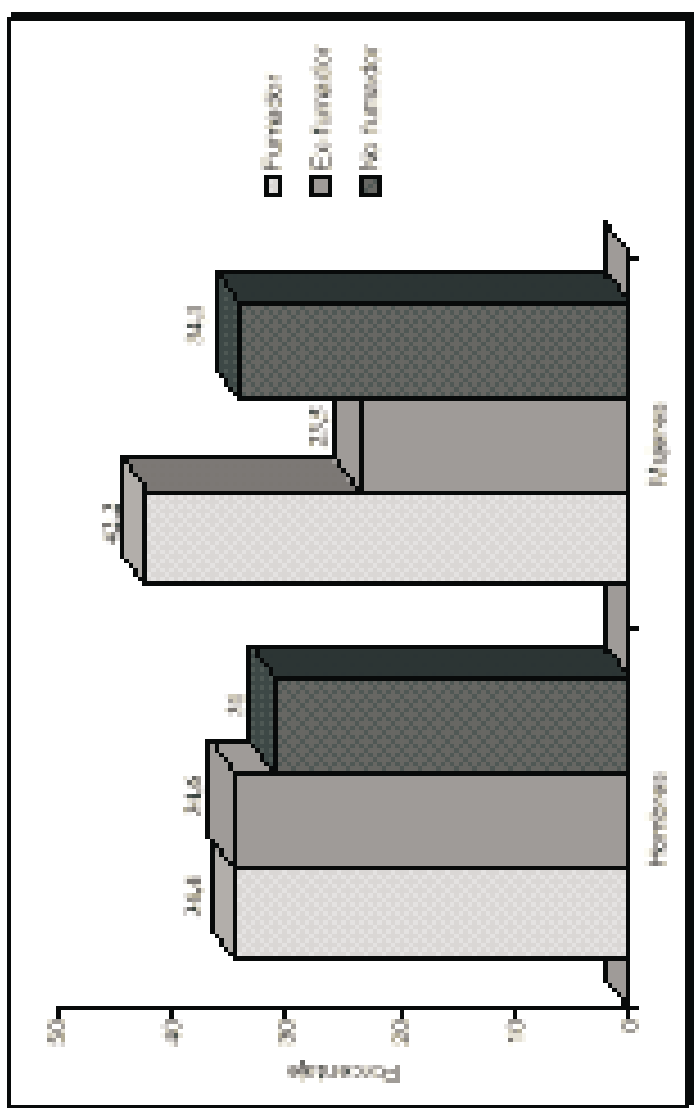




\section{PREVALENCIA DEL CONSUMO DE TABACO EN ESPAÑA}

Como se ha comentado anteriormente en España, según los datos de la ENSE 2001, la prevalencia del tabaquismo en la población española de 16 y más años, fue del 34,4\%. Comparando con los resultados obtenidos en la ENSE 1987, en la que la prevalencia fue del $38,4 \%$, se observa un ligero descenso del consumo de tabaco en España (figura 2).

Los patrones de consumo de tabaco varían considerablemente según el género y la edad. En la ENSE 2001, el porcentaje de hombres fumadores fue del $42,1 \% \mathrm{y}$ del $27,2 \%$ en las mujeres.

Al analizar la evolución del tabaquismo en España de 1987 a 2001, podemos observar que el consumo de tabaco en los hombres ha descendido sensiblemente (de 55\% a $42,1 \%$ ), en contraposición al aumento que ha experimentado el consumo en las mujeres, de $23 \%$ a $27,2 \%$. Este aumento de mujeres fumadoras tendrá repercusiones sanitarias a medio y largo plazo en la mortalidad por cáncer, enfermedades cardiovasculares y respiratorias (figuras 3 y 4 ).
Por grupos de edad, el porcentaje de población fumadora más alto se observa en el grupo de 25 a 44 años $(48,2 \%)$ seguido del grupo de 16 a 24 años $(41,7 \%)$.

Observando la tendencia durante este periodo, en cada uno de los dos géneros, se comprueba que en los hombres la prevalencia del consumo de tabaco ha disminuido en todos los grupos de edad, produciéndose en las mujeres el fenómeno contrario. Por grupos de edad, la prevalencia del consumo es mayor en los hombres, excepto en el grupo de 16 a 24 años (40,8\% hombres, $42,7 \%$ mujeres) en el que el consumo de tabaco es mayor en las mujeres jóvenes. (tabla 1).

Un grupo de especial importancia es la población adolescente y joven. Según la ultima Encuesta sobre Drogas en la Población Escolar, 2000 (Plan Nacional sobre Drogas), el 30,5\% de los escolares de 14-18 años han fumado en el ultimo mes y el $5 \%$ se definen como exfumadores. Las chicas tienen una prevalencia de consumo mayor que los chicos, $35,8 \%$ frente al $25,2 \%$.

El consumo medio de cigarrillos en jóvenes de 14 a 18 años es de 7 (el 47,5\% con-

Tabla 1

Evolución de la prevalencia de consumo de tabaco por 100 habitantes según edad. España 1987-2001

\begin{tabular}{|ccccccc|}
\hline \multirow{2}{*}{$\begin{array}{c}\text { Grupos } \\
\text { de edad }\end{array}$} & \multicolumn{2}{c}{ Ambos sexos } & \multicolumn{2}{c}{ Hombres } & \multicolumn{2}{c|}{ Mujeres } \\
\cline { 2 - 7 } & 1987 & 2001 & 1987 & 2001 & 1987 & 2001 \\
\hline 16 a 44 & 51,8 & 41,7 & 54,5 & 40,8 & 49,0 & 42,7 \\
25 a 44 & 48,9 & 48,2 & 64,2 & 52,6 & 33,6 & 43,5 \\
45 a 64 & 28,0 & 29,7 & 54,0 & 42,6 & 5,1 & 17,5 \\
65 y más & 15,3 & 9,3 & 33,8 & 19,2 & 1,8 & 2,1 \\
Total & 38,4 & 34,4 & 55,1 & 42,1 & 22,9 & 27,2 \\
\hline
\end{tabular}


sume 1-5 cigarrillos al día). La edad media de inicio al consumo se sitúa en los 13,2 años.

Tanto por su función modélica dentro de la sociedad como por su actuación profesional, se ha de resaltar la importancia del consumo de tabaco entre los profesionales sanitarios. En 1998, el 38,9\% de los sanitarios (personal médico y de enfermería) eran fumadores, el 34,7\% en el personal médico y $43,2 \%$ en el de enfermería (figura 5).

Según el género, la prevalencia de fumadores en los hombres sanitarios fue del $34,4 \%$ y del $42,2 \%$ en las mujeres (figura 6).

\section{EFECTOS DEL TABACO SOBRE LA SALUD}

\section{Morbilidad}

El consumo de tabaco se relaciona con más de 25 enfermedades y es el principal factor causante del $30 \%$ de todos los cánceres: cáncer de pulmón (se estima que en un $85 \%$ de los casos es provocado por el tabaquismo), cáncer de la cavidad oral (labios, boca, lengua y garganta), y el cáncer de laringe, faringe, esófago, vejiga y riñones.

También enfermedades respiratorias como la bronquitis crónica, enfisema y asma, son atribuibles al tabaquismo o se ven exacerbadas por él. Así mismo, el consumo de tabaco es un importante factor de riesgo que contribuye a las enfermedades cardiovasculares.

Además de los riesgos generales asociados al tabaquismo, las mujeres fumadoras tienen unos riesgos adicionales para la salud específicos de su género. El tabaquismo contribuye a una reducción de la fertilidad e incrementa el riesgo de menopausia precoz, contribuye a la pérdida de calcio óseo y a la osteoporosis en las mujeres en fase postmenopáusica. El consumo de tabaco cuando se combina con el uso de anticonceptivos ora- les incrementa el riesgo de desarrollar enfermedades cardiovasculares. Se ha asociado el consumo de tabaco durante el embarazo con un mayor riesgo de aborto espontáneo, complicaciones durante el embarazo, muerte fetal, partos prematuros, bajo peso al nacer y muerte del neonato.

La exposición involuntaria al humo del tabaco está provocando un serio problema de salud pública. Esta exposición supone un riesgo considerable para la población no fumadora. La población expuesta tiene un riesgo aumentado de padecer cáncer de pulmón, enfermedades respiratorias y cardiovasculares.

La población infantil que está sometida al aire contaminado por humo de tabaco, presenta una mayor incidencia de infecciones de las vías respiratorias altas, otitis media, sinusitis, bronquitis, neumonías, asma y muerte súbita del lactante.

\section{Mortalidad}

En España, se estima que el consumo de tabaco ha ocasionado la muerte de 621.678 personas de 35 y más años, durante el periodo 1978-1992, lo que significa el 14\% de la tasa de mortalidad global anual.

Sólo en el último año (1992) de este mismo periodo, las muertes atribuibles al consumo de tabaco en ese grupo de población, han pasado de 37.259 a 46.226, lo que representa un $24 \%$ de aumento en la mortalidad debida al consumo de tabaco. Un tercio de estas muertes fueron prematuras con la consiguiente pérdida de años potenciales de vida (entre 10 y 20 años por persona).

Aunque la mayoría de estas muertes ocurrieron en hombres (93,4\% en 1992), hay que destacar que la mortalidad en las mujeres ha experimentado un aumento considerable entre 1978 y 1992, siendo el incremento anual promedio del $6 \%$, frente a una disminución promedio de $-0,2 \%$ en los hombres. 
Por último señalar, que la mortalidad atribuible al tabaquismo en España en 1998, se ha estimado en 55.613 muertes, que representan el $16 \%$ de todos los fallecimientos ocurridos en población de 35 o más años. El $92,5 \%$ de estas muertes se produjeron en hombres (51.431), y el 7,5\% en mujeres (4.182). De todas estas muertes, $26,5 \%$ se debieron a cáncer de pulmón, 20,9\% a enfermedad pulmonar obstructiva crónica, $12,8 \%$ a cardiopatía isquémica, y 9,2\% a enfermedad cerebrovascular.

\section{COSTES SANITARIOS Y SOCIALES DEL CONSUMO DE TABACO}

El Banco Mundial ha evaluado los gastos directos e indirectos de las muertes prematuras y de la morbilidad atribuibles al tabaquismo, estimando que un aumento de 1.000 toneladas en el consumo de tabaco representa 2,6 millones de dólares de beneficios y 29,8 millones de costes. Esto supone una pérdida neta de 27,2 millones de dólares.

En 1988, se estimó que la sola reducción del consumo de tabaco en un $10 \%$ evitaría costes equivalentes al $0,18 \%$ del PIB en España.

Según un estudio realizado en el año 2001 por la Universidad Pompeu Fabra, los costes sanitarios directos generados por el consumo de tabaco, en seis enfermedades (cáncer de pulmón, enfermedad pulmonar obstructiva crónica, asma, enfermedades cardiovasculares, accidentes cerebrovasculares y bajo peso al nacer), en España en el año 2001 se estimaron entre 437.000 y 604.000 millones de pesetas (según las distintas fracciones atribuibles al consumo de tabaco en las enfermedades estudiadas).

\section{MARCO INTERNACIONAL}

En la Primera Conferencia Europea sobre Política del Tabaco, celebrada en Madrid en
1988, se adoptó una Carta Europea contra el Tabaco en la que se reconocía el derecho de la población a ser protegida, no sólo de las enfermedades causadas por el tabaco, sino también de la contaminación creada por el humo del tabaco. Se recomendaron diez estrategias a seguir para posibilitar los derechos establecidos en la Carta, así como las medidas a tomar para desarrollar cada estrategia.

Las principales estrategias propuestas en la Carta de Madrid han sido ratificadas en la II Conferencia Europea y I Iberoamericana sobre Tabaco o Salud celebrada en Canarias en 1999, y en el I Congreso Nacional sobre la Prevención y el Tratamiento del Tabaquismo celebrado en Sevilla en 2001.

La recomendación de la Organización Mundial de la Salud (OMS) es contundente: deben ponerse en marcha programas de disminución del tabaquismo que integren acciones educativas, legislativas y asistenciales. Desde la Oficina Regional Europea se destaca que una reducción en el consumo de tabaco es la más importante medida de Salud Pública que los países pueden adoptar para beneficio de su salud y su economía.

La Oficina Regional Europea de la OMS incluyó entre los objetivos de la estrategia «Salud para Todos 2000» la reducción del hábito de fumar (Objetivo 16). En el documento Salud 21, la OMS vuelve a incorporar entre sus prioridades las intervenciones para reducir el consumo de tabaco y los daños para la salud que se derivan del tabaquismo. En su objetivo 12, propone: reducir los daños derivados del alcohol, las drogas y el tabaco; y en particular el objetivo 12.1 señala que para el año 2015, el porcentaje de no fumadores debe ser, al menos, el $80 \%$ entre las personas mayores de 15 años y prácticamente el $100 \%$ de los menores de 15 años.

En la 52 sesión del Comité Regional Europeo de la Organización Mundial de la Salud celebrada en Copenhague en septiem- 
bre de 2002, se acordó mediante Resolución, la «Estrategia Europea para el Control del Tabaquismo», que establece un marco estratégico referencial para el control del tabaquismo en la región Europea, con una serie de medidas que deben ser contempladas en los correspondientes planes nacionales, según sus necesidades y realidades, para continuar intensificando su tarea y seguir explorando acciones innovadoras. Tiene en consideración los tres anteriores Planes de Actuación para una Europa sin Tabaco y sus evaluaciones, los principios rectores de la Declaración de Varsovia y es acorde con la estructura y contenido del Convenio Marco para el Control del Tabaco.

El Convenio Marco para el Control del Tabaco representa un instrumento jurídico internacional para el control mundial del tabaquismo y complemento global a los programas y planes de control del tabaquismo a nivel nacional, que surge en 1996 con la resolución WHA49.17 ante la necesidad de dar una respuesta mundial a este problema que no tiene fronteras, y que liderado por la OMS el proceso de su desarrollo desde la resolución EB103.R11 de la Asamblea Mundial de la Salud, se adoptará en el año 2003 por los 192 Estados miembros, al objeto de hacer progresar sinérgicamente las políticas nacionales de salud pública.

Además del firme apoyo a las políticas de la OMS, la Unión Europea promueve acciones de protección de la salud y control del tabaquismo mediante Recomendaciones a los Estados miembros, y desarrolla su capacidad legislativa a través de la promulgación de Directivas que deben ser transpuestas a las respectivas normativas nacionales.

Cada año, los productos del tabaco son responsables de 1,2 millones de muertes ( $14 \%$ de todos los fallecimientos) en la Región Europea de la OMS. Se prevé que, a menos que se adopten medidas más estrictas, estos productos serán responsables de 2 millones de muertes anuales $(20 \%$ de todos los fallecimientos) para el año 2020. Además de enfermedad y muerte, provocan unas pérdidas económicas netas en el mundo de al menos 200.000 millones de dólares (USD) al año.

Para conseguir disminuir la elevada prevalencia (más del $30 \%$ en población adulta), se precisa reducir la accesibilidad tan extendida de los productos de tabaco, y poner especial atención en jóvenes y mujeres.

En España, desde la publicación del Real Decreto 192/1988 del 4 de marzo, sobre limitaciones en la venta y uso del tabaco para protección de la salud de la población, se han venido incrementando las actividades dirigidas a disminuir el consumo de tabaco en todos los ámbitos sociales del Estado, de las Comunidades Autónomas y los Ayuntamientos, y a fomentar una cultura sin tabaco. El Plan Nacional de Prevención y Control del Tabaquismo pretende impulsar y coordinar todas las acciones encaminadas a prevenir y controlar el tabaquismo en España.

\section{CONCLUSIONES}

En los últimos 15 años las diferentes administraciones y en especial los distintos gobiernos autonómicos, han desarrollado programas de actuación para la prevención del tabaquismo. Aunque su grado de desarrollo es heterogéneo y los recursos empleados muy desiguales, estas iniciativas suponen sin duda oportunidades que favorecen e impulsan las políticas para la prevención y el control del tabaquismo que constituyen los objetivos prioritarios del Plan Nacional de Prevención y Control del Tabaquismo.

La mayoría de las Comunidades y Ciudades Autónomas están realizando intervenciones que tienen básicamente los mismos objetivos y proponen fundamentalmente las mismas líneas de actuación. 
Es por tanto de gran utilidad, aprovechar la experiencia acumulada por todas las administraciones públicas en el desarrollo de este tipo de intervenciones y especialmente los logros de aquellas Comunidades que han podido llevar a cabo programas más sistemáticos de actuación, siendo a la vez necesario reforzar las políticas de control del tabaquismo en España, y aumentar los recursos humanos y materiales destinados a la prevención del consumo de tabaco y a reducir su prevalencia, para lograr desarrollar este Plan Nacional.

La preocupación y actividad de numerosas sociedades científicas y la progresiva implicación de las asociaciones sociales en las actuaciones destinadas a la prevención del tabaquismo, es sin duda otro instrumento de incuestionable valor que el Plan Nacional contempla.

Un ejemplo de la importancia de estos movimientos asociativos lo representa el Comité Nacional de Prevención del Tabaquismo (CNPT). Actualmente lo constituye 33 organizaciones, principalmente asociaciones de profesionales sanitarios, que mantiene vínculos con otras organizaciones implicadas e interesadas en la prevención del tabaquismo. Además, forma parte de la Red Europea de Prevención del Tabaquismo, que agrupa a coaliciones similares de los diversos países de la Unión Europea.

Desde su fundación, el CNPT ha trabajado para ampliar la prevención del tabaquismo en España y ha desarrollado acciones de educación e información dirigidas a la población, de formación y trabajo con los profesionales de la salud, de colaboración con las autoridades sanitarias, y de contacto con los representantes políticos de la población.

La existencia de la Estrategia Europea para el Control del Tabaquismo y el Convenio Marco para el Control del Tabaco, de la Organización Mundial de la Salud, así como las iniciativas legislativas de la Unión Euro- pea, son también aspectos que propician, refuerzan y favorecen el desarrollo del Plan Nacional.

El objetivo principal del Plan Nacional es conseguir la armonización entre las diferentes Administraciones para afrontar globalmente el control y prevención del tabaquismo, evitando la dispersión de competencias, la insuficiente difusión sistemática de las acciones realizadas, la escasez de recursos disponibles para afrontar un problema de salud pública de tal magnitud, la falta de homogeneidad en algunos criterios de seguimiento y evaluación del control del tabaquismo, o las dificultades para realizar un seguimiento eficaz del cumplimiento de la normativa que regula la venta, el consumo, y la publicidad del tabaco.

Es necesario impulsar programas que eviten la incorporación al consumo (o al menos retrasen la edad de inicio) y también actividades destinadas a disminuir la prevalencia del tabaquismo, facilitando la deshabituación de la población fumadora. Este descenso en la prevalencia es el único mecanismo para reducir un gran número de enfermedades y muertes, en su mayoría prematuras, atribuidas al tabaquismo. Conviene que estas intervenciones, incluyan acciones especificas por género para evitar que la prevalencia del consumo de tabaco siga aumentando entre las mujeres.

Es fundamental que las intervenciones sean multisectoriales y de amplio alcance, para garantizar su máxima eficacia. También es necesario que sean sólidamente mantenidas, sabiendo que la reducción del consumo se refleja en el tiempo como una disminución de las enfermedades y muertes asociadas al tabaquismo.

Se pone de manifiesto de manera constante en foros nacionales e internacionales, la necesidad de incrementar las actividades informativas y educativas, los desarrollos normativos, ampliar las restricciones para la 
venta, el consumo y la publicidad del tabaco, aumentar los recursos destinados a la deshabituación de la población fumadora, incrementar la investigación para mejorar nuestro conocimiento sobre los factores que determinan el inicio y la consolidación del consumo de tabaco (especialmente en la población joven y entre las mujeres).

La gravedad del problema y la posibilidad de obtener ganancias de salud, mediante políticas estables y comprometidas, obligan a intervenir decididamente. Es un gran reto, como grande debe ser el esfuerzo ante la existencia de poderosos obstáculos.

\section{BIBLIOGRAFÍA}

1. American Psychiatric Association. Diagnostic and Statistical Manual of Mental Disorders. 4th edition (DSM-IV). Washington: American Psychiatric Association; 1995

2. Barnum HN. La política del Banco Mundial sobre el tabaco. IX Conferencia sobre el Mundial sobre el Tabaco en la Salud. París; 1994.

3. Gil López E, Robledo de Dios T, Rubio Colavida JM, Bris Coello MR, Espiga López I, Saiz Martínez-Acitores I. Prevalencia del consumo de tabaco en los profesionales sanitarios del Insalud 1998, España. Prev Tab 2000; 2: 22-31.

4. González Enríquez J, Villar Alvarez F, Banegas Banegas JR, Rodríguez Artalejo F, Martín Moreno JM. Tendencia de la mortalidad atribuible al consumo de tabaco en España, 1978-1992: 600.000 muertes en 15 años. Med Clin (Barc) 1997; 109:577-82.

5. Banegas Banegas JR, Díaz Gañán L, RodriguezArtalejo F, González Enríquez J, Graciani Pérez Regadera A, Villar Alvarez F. Mortalidad atribuible al tabaquismo en España en 1998. Med Clin (Barc) 2001; 117:692-4.

6. Ministerio de Sanidad y Consumo. Encuesta Nacional de Salud de España 2001. Madrid: Ministerio de Sanidad y Consumo (pendiente de publicación).

7. Ministerio de Sanidad y Consumo. Encuesta Nacional de Salud de España 1997. Madrid: Ministerio de Sanidad y Consumo; 1998.
8. Ministerio de Sanidad y Consumo. Encuesta Nacional de Salud de España 1995. Madrid: Ministerio de Sanidad y Consumo; 1996.

9. Ministerio de Sanidad y Consumo. Encuesta Nacional de Salud de España 1993. Madrid: Ministerio de Sanidad y Consumo; 1995.

10. Ministerio de Sanidad y Consumo. Encuesta Nacional de Salud de España 1987. Madrid: Ministerio de Sanidad y Consumo; 1989.

11. Ministerio del Interior. Encuesta sobre Drogas a la Población Escolar 2000. Madrid: Ministerio de Interior. Disponible en: www.mir.es/pnd.

12. Comité Nacional para la Prevención del Tabaquismo. Libro Blanco sobre el Tabaquismo en España. Barcelona: Glosa; 1998.

13. Organización Mundial de la Salud. Salud 21: El marco político de salud para todos de la Región Europea de la OMS. Madrid: Ministerio de Sanidad y Consumo, 1999.

14. Organización Mundial de la Salud. Se puede lograr: Una Europa libre de tabaco. Madrid: Ministerio de Sanidad y Consumo; 1992.

15. Organización Mundial de la Salud. Tercer Plan de Actuación para una Europa sin Tabaco 1997-2001. Madrid: Ministerio de Sanidad y Consumo; 1999.

16. Organización Mundial de la Salud. Estrategia Europea para el Control del Tabaco. Copenhague: Organización Mundial de la Salud; 2002.

17. Organización Mundial de la Salud: Los objetivos de la salud para todos. Madrid: Ministerio de Sanidad y Consumo; 1987.

18. Organización Mundial de la Salud: Perfiles sobre tabaco en la Región Europea. Ginebra: Organización Mundial de la Salud; 1996.

19. Rovira J, Escribano M. Estimación del impacto económico a largo plazo de una reducción del consumo de tabaco. Madrid: Ministerio de Sanidad y Consumo; 1989.

20. World Health Organization. International Statistical Classification of Diseases and Related Health Problems, 10th revision. Geneva: World Health Organization; 1992. 
PRINCIPIOS DEL PLAN NACIONAL DE PREVENCIÓN Y CONTROL DEL TABAQUISMO

\section{Principios fundamentales:}

- Responde a un compromiso institucional.

- Está liderado por las autoridades sanitarias para promover y coordinar todas las acciones que se desarrollen en este campo.

- Participa de las orientaciones y estrategias internacionales de la Organización Mundial de la Salud y de la Unión Europea.

- Cuenta con un enfoque global del problema, promoviendo la colaboración intersectorial y estableciendo medidas graduales para disminuir las desigualdades.

- Pretende promover la salud, la calidad de vida, y la participación social.

\section{OBJETIVOS DEL PLAN NACIONAL DE PREVENCIÓN Y CONTROL DEL TABAQUISMO}

\section{Objetivos Generales y Específicos:}

\section{Disminuir la prevalencia tabáquica}

1.1. Prevenir la incorporación de nuevos fumadores y fumadoras.

1.2. Retrasar la edad de inicio del hábito tabáquico.

1.3. Facilitar el abandono de la dependencia tabáquica.

2. Proteger la salud de la población del aire contaminado por humo de tabaco (ACHT)

2.1. Evitar la exposición de la población al aire contaminado por humo de tabaco.
2.2. Potenciar los espacios sin humo

2.3. Fomentar la norma social de no fumar

3. Potenciar la coordinación y la participación

3.1. Coordinación institucional

3.2. Coordinación intersectorial

3.3. Coordinación internacional

3.4. Participación social.

Para alcanzar cada uno de estos objetivos específicos, se han definido diversas actuaciones, agrupadas en estrategias (informativa, educativa y formativa, asistencial, legislativa, coordinación y participación, e investigación y evaluación).

\section{Objetivo General 1: Disminuir la prevalencia tabáquica}

Para el año 2007, el número de fumadores y fumadoras de 16 y más años se habrá reducido en 6 puntos porcentuales, situando la prevalencia por debajo del $28 \%$.

\section{Objetivos Específicos:}

1.1. Prevenir la incorporación de nuevos fumadores y fumadoras

En el año 2007, la proporción de personas fumadoras en el grupo de 16 a 24 años, habrá disminuido 6 puntos porcentuales, situándose por debajo del $36 \%$.

1.2. Retrasar la edad de inicio del hábito tabáquico

Para el año 2007, la edad media de inicio en el hábito tabáquico se habrá retrasado a los 14 años.

1.3. Facilitar el abandono de la dependencia tabáquica Para el año 2007, la proporción de población ex fumadora aumentará al menos en 6 puntos, situándose por encima del $23 \%$. 


\section{Actuaciones y estrategias para lograr el Objetivo Específico 1.1: Prevenir la incorporación de nuevos fumadores y fumadoras}

\begin{tabular}{|c|}
\hline Estrategia Informativa \\
\hline $\begin{array}{l}\text { Difundir amplia y periódicamente la información sobre los efectos del consumo de tabaco en la salud } \\
\text { de la población fumadora voluntaria e involuntaria, y los beneficios de no fumar, promoviendo el uso } \\
\text { de las nuevas tecnologías de la información. }\end{array}$ \\
\hline $\begin{array}{l}\text { Ampliar y difundir, exhaustiva y reiteradamente, la información sobre legislación vigente en materia } \\
\text { de tabaco. }\end{array}$ \\
\hline $\begin{array}{l}\text { Facilitar la información desde un enfoque multidisciplinar, integrándola en las diversas actividades de } \\
\text { los servicios sanitarios, de prevención de riesgos laborales, farmacias, movimientos comunitarios, } \\
\text { ONGs, asociaciones de consumidores. }\end{array}$ \\
\hline $\begin{array}{l}\text { Difundir información sobre los efectos perniciosos de la exposición pasiva al humo del tabaco, desta- } \\
\text { cando la especial importancia de no fumar durante el embarazo, ni en presencia de niños, ancianos y } \\
\text { enfermos. }\end{array}$ \\
\hline $\begin{array}{l}\text { Sensibilizar a padres, docentes, sanitarios y líderes sociales del papel modélico que representan en la } \\
\text { adquisición de hábitos saludables. }\end{array}$ \\
\hline $\begin{array}{l}\text { Elaborar materiales de apoyo impresos y audiovisuales, con mensajes adaptados a las características } \\
\text { de edad, género y rol, asegurando su distribución periódica y accesibilidad: centros sanitarios, docen- } \\
\text { tes, de ocio, farmacias, etc. }\end{array}$ \\
\hline Procurar el apoyo de los medios de comunicación social para realizar campañas coordinadas y periódicas. \\
\hline $\begin{array}{l}\text { Potenciar la celebración del Día Mundial Sin Tabaco en todos los ámbitos, instalando mesas informati- } \\
\text { vas en centros de salud y hospitales, realizando mediciones de monóxido de carbono en aire espirado. }\end{array}$ \\
\hline Ofertar teléfonos gratuitos de información sobre prevención del tabaquismo. \\
\hline Estrategia Educativa Formativa \\
\hline $\begin{array}{l}\text { Potenciar el desarrollo de programas de prevención del tabaquismo atendiendo a las características de } \\
\text { edad, género y rol. }\end{array}$ \\
\hline $\begin{array}{l}\text { Concienciar a padres, docentes, sanitarios y líderes sociales del papel modélico que representan, fo- } \\
\text { mentando su implicación activa. }\end{array}$ \\
\hline $\begin{array}{l}\text { Facilitar formación a profesionales sanitarios de Atención Primaria y Especializada sobre el problema } \\
\text { de salud pública que representa el tabaquismo, las tendencias actuales de la edad de inicio y el au- } \\
\text { mento del consumo en mujeres jóvenes, señalando la importancia de su intervención para evitar la ad- } \\
\text { quisición del hábito en la población no fumadora. }\end{array}$ \\
\hline $\begin{array}{l}\text { Incentivar la intervención preventiva y educadora de profesionales sanitarios, reforzando en la pobla- } \\
\text { ción (jóvenes, mujeres) el comportamiento de no fumar. }\end{array}$ \\
\hline $\begin{array}{l}\text { Facilitar formación al personal docente sobre prevención del tabaquismo, y potenciar la integración de } \\
\text { la Educación para la Salud en la Escuela. }\end{array}$ \\
\hline Patrocinar la realización de actividades sin tabaco desde las Consejerías de Cultura y Deportes. \\
\hline $\begin{array}{l}\text { Introducir la formación específica sobre tabaco/salud y consejo antitabaco, en los centros de forma- } \\
\text { ción de profesionales sanitarios (Facultades de Medicina, Odontología, Escuelas Universitarias de En- } \\
\text { fermería, Formación Profesional, etc.), prestando especial atención a la problemática del tabaco en la } \\
\text { mujer, suministrando materiales de apoyo adecuados. }\end{array}$ \\
\hline $\begin{array}{l}\text { Formar al personal docente, monitores de tiempo libre y líderes juveniles sobre las ventajas y benefi- } \\
\text { cios de no fumar, la publicidad y las técnicas de resistencia a la presión. }\end{array}$ \\
\hline
\end{tabular}




\section{Estrategia Asistencial}

Potenciar la intervención de profesionales sanitarios de Atención Primaria y Especializada, facilitando el Consejo Sanitario Antitabaco a usuarios y reforzando el comportamiento de no fumar.

Estrategia Legislativa

Establecer lugares de trabajo (docentes, sanitarios, públicos y de ocio) como espacios libres de humo. Garantizar el cumplimiento de la legislación vigente sobre limitaciones de la venta y consumo de tabaco, contando con la participación de todos los sectores implicados: consumo, trabajo, educación, salud pública, policía municipal, guardia civil, etc.

Ampliar el marco legislativo estatal implantando gradualmente la prohibición de la publicidad directa e indirecta, la promoción y el patrocinio de los productos del tabaco.

Excluir del Indice de Precios de Consumo (IPC), los productos del tabaco.

Ampliar el marco legislativo estatal, unificando la prohibición de venta de tabaco, a menores de 18 años.

Establecer medidas fiscales a nivel nacional de aumento del precio del tabaco.

Promover la supresión de máquinas expendedoras de tabaco (que no distinguen la edad del comprador), contemplando la venta personalizada como forma principal de adquisición de estos productos.

Prohibir la venta de cigarrillos sueltos, estableciendo como unidad única de venta las cajetillas de 20.

Estrategia Coordinación Participación

Incentivar políticas de actividades de ocio para adolescentes y jóvenes en locales sin humo.

Establecer una política gradual de espacios sin humo encaminada a conseguir una sociedad libre de tabaco.

Promover la acreditación como espacios sin humo de aquellos locales donde se realicen actividades de ocio principalmente para jóvenes y adolescentes.

Promover la participación de la comunidad, de colectivos sociales y asociaciones profesionales en el desarrollo de actividades de prevención del tabaquismo.

\section{Estrategia Investigación Evaluación}

Investigar la motivación, causas del inicio y la consolidación, del hábito de fumar en jóvenes y adolescentes, atendiendo a la edad y género.

Realizar estudios epidemiológicos y encuestas que faciliten información sobre las causas que motivan el consumo de tabaco. 


\section{Actuaciones y estrategias para lograr el Objetivo Específico 1.2: Retrasar la edad de inicio del hábito tabáquico}

\begin{tabular}{|c|}
\hline Estrategia Informativa \\
\hline $\begin{array}{l}\text { Difundir la información sobre los beneficios de no fumar, o en su defecto el beneficio del retraso en el } \\
\text { inicio del hábito tabáquico, especialmente en el entorno familiar y docente de adolescentes y jóvenes. }\end{array}$ \\
\hline Estrategia Educativa Formativa \\
\hline $\begin{array}{l}\text { Concienciar y proporcionar información a profesionales docentes y sanitarios sobre la importancia de } \\
\text { retrasar la edad de inicio del hábito tabáquico. }\end{array}$ \\
\hline Diseñar programas de prevención del tabaquismo específicos para niños/as, adolescentes y jóvenes. \\
\hline $\begin{array}{l}\text { Realizar intervenciones en colaboración con las Asociaciones de Madres y Padres del Alumnado, di- } \\
\text { rigidas a reforzar sus conocimientos sobre tabaquismo, incidiendo especialmente en los beneficios de } \\
\text { retrasar la edad de inicio y de la experimentación en el consumo de tabaco. }\end{array}$ \\
\hline $\begin{array}{l}\text { Facilitar formación al personal docente, monitores de tiempo libre y líderes juveniles sobre las venta- } \\
\text { jas y beneficios de no fumar, publicidad y técnicas de resistencia a la presión. }\end{array}$ \\
\hline Estrategia Asistencial \\
\hline $\begin{array}{l}\text { Potenciar la intervención de profesionales sanitarios en programas educativos comunitarios, reforzan- } \\
\text { do el comportamiento de no fumar y los perjuicios que ocasiona el consumo de tabaco. }\end{array}$ \\
\hline Fomentar el Consejo Antitabaco de modo sistemático y su registro en los servicios sanitarios. \\
\hline Estrategia Legislativa \\
\hline $\begin{array}{l}\text { Reforzar el conocimiento y cumplimiento de la legislación respecto a la prohibición de vender tabaco } \\
\text { a los menores de } 18 \text { años. }\end{array}$ \\
\hline $\begin{array}{l}\text { Restringir la accesibilidad y disponibilidad del tabaco, unificando en todo el territorio nacional la pro- } \\
\text { hibición de venta de tabaco a la población menor de } 18 \text { años. }\end{array}$ \\
\hline $\begin{array}{l}\text { Ampliar el marco legislativo estatal implantando de modo gradual la prohibición de la publicidad di- } \\
\text { recta e indirecta, la promoción y el patrocinio de los productos del tabaco. }\end{array}$ \\
\hline $\begin{array}{l}\text { Promover la supresión de las máquinas expendedoras de tabaco (que no distinguen la edad del com- } \\
\text { prador), delimitando la venta personalizada como forma principal de adquisición de estos productos. }\end{array}$ \\
\hline Establecer medidas fiscales nacionales de aumento del precio del tabaco. \\
\hline Garantizar el cumplimiento de la legislación vigente sobre limitaciones de la venta y consumo de tabaco. \\
\hline Estrategia Coordinación Participación \\
\hline $\begin{array}{l}\text { Promover la acreditación como Espacios Sin Humo de aquellos locales donde se realicen actividades } \\
\text { de ocio para jóvenes y adolescentes. }\end{array}$ \\
\hline $\begin{array}{l}\text { Fomentar iniciativas y participación en proyectos de ámbito nacional e internacional que permitan el } \\
\text { intercambio de conocimientos y estrategias de prevención del inicio (Clases Sin Humo, etc.). }\end{array}$ \\
\hline $\begin{array}{l}\text { Obtener el compromiso de autoridades, personalidades y otros líderes sociales, de no fumar en actos } \\
\text { públicos. }\end{array}$ \\
\hline $\begin{array}{l}\text { Convocar anualmente subvenciones a proyectos y actividades de prevención del tabaquismo, promo- } \\
\text { vidos sin ánimo de lucro, por colectivos de jóvenes y ONGs. }\end{array}$ \\
\hline Estrategia Investigación Evaluación \\
\hline Investigar la motivación y causas del inicio del hábito tabáquico en jóvenes y adolescentes, según género. \\
\hline Realizar encuestas que permitan conocer datos sobre el inicio y los factores influyentes, según género. \\
\hline Desarrollar sistemas de información y monitorización que permitan la evaluación de las actuaciones \\
\hline
\end{tabular}




\section{Actuaciones y estrategias para lograr el Objetivo Específico 1.3: Facilitar el abandono de la dependencia tabáquica}

\begin{tabular}{|c|}
\hline \\
\hline $\begin{array}{l}\text { Aumentar la sensibilización, estimulando dejar de fumar y facilitando información sobre los medios } \\
\text { de ayuda existentes. }\end{array}$ \\
\hline $\begin{array}{l}\text { Facilitar información adaptada a las características de los diferentes grupos poblacionales, resaltando } \\
\text { los beneficios de no fumar más destacados en cada uno de ellos (jóvenes, mujeres, enfermos, colecti- } \\
\text { vos modélicos, etc). }\end{array}$ \\
\hline $\begin{array}{l}\text { Concienciar a padres y madres, docentes, sanitarios y líderes sociales del papel modélico que repre- } \\
\text { sentan, de la influencia que ejercen en su entorno, y de los beneficios de abandonar su dependencia. }\end{array}$ \\
\hline $\begin{array}{l}\text { Difundir información sobre los efectos del tabaco en la salud de los fumadores activos y pasivos, des- } \\
\text { tacando la especial importancia durante el embarazo, en presencia de niños, ancianos y enfermos. }\end{array}$ \\
\hline $\begin{array}{l}\text { Elaborar mensajes para potenciar los espacios sin humo como factor contribuyente a la disminución y } \\
\text { abandono del consumo de tabaco. }\end{array}$ \\
\hline Ofertar teléfonos gratuitos de información y de apoyo al abandono de la dependencia tabáquica. \\
\hline Estrategia Educativa Formativa \\
\hline $\begin{array}{l}\text { Reforzar el rol modélico de profesionales sanitarios, motivándoles para que desarrollen programas de } \\
\text { tratamiento de la dependencia tabáquica. }\end{array}$ \\
\hline $\begin{array}{l}\text { Desarrollar programas formativos específicos, dirigidos a colectivos modélicos (sanitarios, docentes, } \\
\text { asociaciones de padres y madres), para ayudarles a dejar de fumar, y motivarles para intervenir en sus } \\
\text { respectivos ámbitos. }\end{array}$ \\
\hline Promover los programas de ayuda al abandono tabáquico en el ámbito laboral. \\
\hline Estrategia Asiste \\
\hline $\begin{array}{l}\text { Impulsar el reconocimiento sanitario de la dependencia tabáquica como enfermedad crónica y motivar } \\
\text { el desarrollo de programas de apoyo al abandono del tabaco en Atención Primaria. }\end{array}$ \\
\hline $\begin{array}{l}\text { Garantizar el abordaje global y el tratamiento de la dependencia tabáquica mediante su inclusión en } \\
\text { las prestaciones sanitarias del Sistema Nacional de Salud (SNS). }\end{array}$ \\
\hline $\begin{array}{l}\text { Impulsar la cumplimentación de la historia de consumo de tabaco en la historia clínica y la aplicación } \\
\text { y registro sistemático del Consejo Sanitario Antitabaco. }\end{array}$ \\
\hline $\begin{array}{l}\text { Garantizar la aplicación de la intervención breve (Consejo sistematizado breve y firme al fumador, su- } \\
\text { ministrando material de autoayuda y haciendo un seguimiento), que se ofertará a la población fuma- } \\
\text { dora que acuda al centro de salud independientemente de la patología que presente. }\end{array}$ \\
\hline $\begin{array}{l}\text { Elaborar protocolos de diagnóstico, tratamiento y seguimiento homogéneos que permitan monitorizar } \\
\text { y evaluar el desarrollo de esta actividad. }\end{array}$ \\
\hline $\begin{array}{l}\text { Elaborar materiales de autoayuda (guías para dejar de fumar) y asegurar una distribución y reposición } \\
\text { adecuada y continua que garanticen la accesibilidad a toda la población fumadora. }\end{array}$ \\
\hline $\begin{array}{l}\text { Regular las unidades de deshabituación tabáquica garantizando su acreditación, dotación de medios y } \\
\text { de personal multidisciplinar formado, y estableciendo criterios de derivación. Tendrán funciones asis- } \\
\text { tenciales, de formación de profesionales sanitarios y de investigación. Deberán estar integradas en la } \\
\text { red de servicios de salud del SNS. }\end{array}$ \\
\hline $\begin{array}{l}\text { Promover la realización de programas de tratamiento de la dependencia tabáquica dirigidos a colecti- } \\
\text { vos específicos: sanitarios, docentes, profesionales de los medios de comunicación, líderes sociales, } \\
\text { etc. }\end{array}$ \\
\hline
\end{tabular}


Promover la puesta en marcha de programas de apoyo a través de nuevas tecnologías (internet).

Facilitar el desarrollo de otras intervenciones de apoyo al abandono del tabaco que hayan demostrado su eficacia.

Impulsar programas de ayuda desde los servicios de salud laboral, facilitando la asistencia del personal fumador a las consultas o programas en el horario laboral.

Elaborar programas específicos para mujeres embarazadas o que toman anticonceptivos orales, mediante los servicios de obstetricia, matronas, orientación familiar, preparación al parto, etc.

\section{Estrategia Legislativa}

Incluir la vigilancia del cumplimiento de la normativa vigente en materia de venta y consumo de tabaco entre las competencias de los distintos órganos inspectores implicados (consumo, trabajo, educación, salud pública, policía municipal, guardia civil, etc.).

Ampliar el marco legislativo estatal implantando de modo gradual la prohibición total de la publicidad directa e indirecta, la promoción y el patrocinio de los productos del tabaco.

\section{Estrategia Coordinación Participación}

Apoyar las intervenciones que desde las organizaciones ciudadanas se desarrollan en este tema.

Establecer una política gradual de espacios sin humo (ámbito público, laboral, social y de ocio), hasta conseguir la totalidad de los espacios libres de humo de tabaco.

Incluir en la cartera de servicios de Atención Primaria el tratamiento de la dependencia tabáquica, asignando los recursos humanos y económicos específicos.

Establecer un sistema de acreditación de las unidades de tratamiento de la dependencia tabáquica.

Impulsar la participación de los centros hospitalarios en la Red Europea de Hospitales Sin Tabaco, estimulándoles a desarrollar actividades establecidas en el Decálogo Europeo y a la acreditación de sus centros.

Promover la participación en programas de intervención comunitaria (Quit \& Win, etc.).

\section{Estrategia Investigación Evaluación}

Fomentar la investigación en el abandono de la dependencia tabáquica, atendiendo a las características por grupos etáreos y de género.

Realizar estudios que permitan conocer los factores que influyen en el abandono, según edad y género. 


\section{Objetivo General 2: Proteger la salud de la población del aire contaminado por humo de tabaco}

Para el año 2007, al menos el $65 \%$ de la población considerará que está protegida de la exposición al aire contaminado por humo de tabaco

\section{Objetivos Específicos:}

2.1. Evitar la exposición de la población al aire contaminado por humo de tabaco

Para el año 2004, se habrán desarrollado normativas que regulen el consumo de tabaco en todos los ámbitos públicos

\subsection{Potenciar los espacios sin humo}

Para el año 2005, al menos el 70\% de las empresas dispondrán de espacios libres de humo

\subsection{Fomentar la norma social de no fumar}

Para el año 2005, el 75\% de la población considerará que el tabaco es menos aceptado en su entorno social.

\section{Actuaciones y estrategias para lograr el Objetivo Específico 2.1. Evitar el tabaquismo involuntario}

\begin{tabular}{|l|}
\hline \multicolumn{1}{|c|}{ Estrategia Informativa } \\
\hline Informar a la población de las consecuencias de convivir en espacios donde otros fuman. \\
\hline Fomentar los hogares y espacios de ocio sin tabaco. \\
\hline Informar a la población sobre su derecho a respirar aire no contaminado por humo del tabaco. \\
\hline Difundir la normativa sobre espacios sin humo. \\
\hline \multicolumn{1}{|c|}{ Estrategia Educativa Formativa } \\
\hline $\begin{array}{l}\text { Facilitar formación a profesionales docentes, a madres y padres, sobre los perjuicios de la exposición } \\
\text { involuntaria al aire contaminado por humo del tabaco, motivando su intervención activa. }\end{array}$ \\
\hline Estrategia Asistencial \\
\hline $\begin{array}{l}\text { Fomentar entre profesionales sanitarios de Atención Primaria y Especializada la "intervención mínima } \\
\text { o intervención breve", preguntando a todos los pacientes sobre su exposición al aire contaminado por } \\
\text { humo de tabaco en el hogar o lugar de trabajo, aconsejando como minimizar el riesgo que conlleva. }\end{array}$ \\
\hline \multicolumn{1}{c|}{ Estrategia Legislativa } \\
\hline Promover la inclusión del humo ambiental del tabaco en el listado de sustancias nocivas ambientales. \\
\hline $\begin{array}{l}\text { Favorecer la creación de una medida comunitaria para clasificar el humo ambiental del tabaco, como } \\
\text { agente carcinógeno del lugar de trabajo, a través de la Agencia Europea de Seguridad y Salud en el } \\
\text { Trabajo. }\end{array}$ \\
\hline $\begin{array}{l}\text { Al no existir un nivel seguro de exposición al humo ambiental del tabaco, no se aceptarán las estrate- } \\
\text { gias de regulación de ventilación, diseño del espacio, etc., que se alegan para evitar el tabaquismo in- } \\
\text { voluntario. }\end{array}$ \\
\hline \multicolumn{1}{c}{ Estrategia Coordinación Participación } \\
\hline $\begin{array}{l}\text { Fomentar iniciativas de colectivos comunitarios que promuevan el derecho de no fumar obligadamente. } \\
\text { Buscar alianzas entre políticos y líderes de opinión, para que se manifiesten a favor de una sociedad li- } \\
\text { bre dabaco. }\end{array}$ \\
\hline
\end{tabular}


Fomentar en la población que las celebraciones privadas con asistencia de población infantil, sean sin tabaco.

\section{Estrategia Investigación Evaluación}

Promover la investigación y estudios epidemiológicos acerca del tabaquismo involuntario y su repercusión en la salud de la población.

Fomentar los estudios sobre la toxicidad del aire contaminado por humo de tabaco.

\section{Actuaciones y estrategias para lograr el Objetivo Específico 2.2. Potenciar los espacios sin humo}

\section{Estrategia Informativa}

Facilitar información y normativa sobre espacios sin humo, a la población general y a colectivos y sectores de la sociedad afectados de forma directa: empresas de transporte, administraciones públicas, centros docentes, sanitarios, sociales, deportivos, de ocio, etc.

Desarrollar campañas de información sobre los beneficios que conlleva la creación de ambientes sin humo y los riesgos que provoca el estar en ambientes contaminados por humo de tabaco.

Promover iniciativas que faciliten la información y el respeto por los espacios sin humo.

\section{Estrategia Educativa Formativa}

Promover programas formativos para el personal encargado de velar por el cumplimiento de la normativa (vigilantes, guardias de seguridad, celadores, etc.).

Fomentar actuaciones formativas en el ámbito laboral, dirigidas a las organizaciones sindicales y empresariales.

\section{Estrategia Asistencial}

Incentivar prioritariamente la intervención de los profesionales sanitarios, consiguiendo hacer realidad que los centros sanitarios sean espacios sin humo.

\section{Estrategia Legislativa}

Facilitar los cambios legislativos necesarios para que toda persona vea respetado su derecho a respirar un aire sin humo de tabaco en todos los espacios públicos.

Velar por el cumplimiento de la normativa sobre espacios sin humo en los centros sanitarios, docentes, sociales, de atención al público, y en el ámbito de las administraciones públicas.

Promover las medidas legislativas necesarias para que se establezcan espacios libres de humo en las empresas.

Potenciar una señalización adecuada en todos los espacios sujetos a regulación (prohibición de fumar o zonas para fumadores).

Establecer los niveles de responsabilidad en la vigilancia de la normativa sobre espacios sin humo, diseñando mecanismos ágiles de inspección y respuesta a reclamaciones.

Promover los cambios legislativos para que en el sector de hostelería y restauración se establezcan zonas diferenciadas y limitación del número de plazas para fumadores.

Promover que las entidades locales establezcan y hagan cumplir normas reguladoras sobre limitaciones del consumo de tabaco en espacios públicos.

Establecer los requisitos mínimos de los espacios habilitados para fumar. 


\section{Estrategia Coordinación Participación}

Potenciar que todos los actos en lugares cerrados promovidos o subvencionados por la administración pública, sean declarados sin humo.

Potenciar las actividades de promoción de espacios sin humo en el marco de la red de Ciudades Saludables.

Promover la participación de los sindicatos, unidades de prevención de riesgos laborales y colectivos sanitarios, en las políticas de espacios laborales sin humo.

Proponer a las asociaciones empresariales que consideren la provisión de espacios sin humo para la población trabajadora y clientes, como criterio de calidad en sus empresas.

Promover el establecimiento de zonas diferenciadas para población fumadora y no fumadora en los establecimientos de restauración y hoteleros.

Promocionar con motivo del Día Mundial Sin Tabaco, los reconocimientos a las tareas de personas o entidades, que se han distinguido por la promoción de los espacios sin humo.

\section{Estrategia Investigación Evaluación}

Crear un sistema de información sobre infracciones y sanciones que recoja las actuaciones de las autoridades locales, autonómicas y estatales, al objeto de conocer y evaluar el cumplimiento y seguimiento legislativo sobre espacios sin humo en España.

\section{Actuaciones y estrategias para lograr el Objetivo Específico 2.3. Fomentar la norma social de no fumar}

\section{Estrategia Informativa}

Mantener informada a la población de las ventajas de no fumar, de los perjuicios que ocasiona el tabaco, y del derecho a respirar aire no contaminado por el humo de tabaco.

Diseñar mensajes específicos dirigidos a la población fumadora, concienciando sobre lo que representa la imposición de su hábito tabáquico a los demás.

Difundir información a la población, propiciando posiciones asertivas frente al tabaco, y anteponiendo el diálogo al enfrentamiento.

\section{Estrategia Educativa Formativa}

Desarrollar actuaciones que favorezcan el sentido crítico de la población, desvelando las estrategias de la industria tabaquera tendentes a aumentar la aceptabilidad social del tabaco (minimizar los riesgos del tabaquismo involuntario, presentar como intolerante a la población no fumadora, etc.).

Desarrollar programas que estimulen el diálogo desde una posición asertiva contra el tabaco, buscando el respeto hacia la opción de no fumar.

Analizar críticamente las estrategias seguidas por la industria tabaquera para oponerse a la regulación de los espacios sin humo.

Potenciar la actitud de respeto hacia la población que no fuma, formando parte de otras actividades de formación de hábitos saludables.

\section{Estrategia Asistencial}

Facilitar la intervención de distintos profesionales, potenciando las actitudes saludables y facilitando los recursos para saber resistir a la presión de grupo, de la industria tabaquera, y de la publicidad. 


\begin{tabular}{|l|}
\hline \multicolumn{1}{|c|}{ Estrategia Legislativa } \\
\hline Mantener informada a la población de la normativa vigente. \\
\hline Cumplir la legislación actual y ampliar el marco legislativo progresivamente. \\
\hline Facilitar mecanismos ágiles de consulta, inspección y sanción. \\
\hline \multicolumn{1}{c|}{ Estrategia Coordinación Participación } \\
\hline $\begin{array}{l}\text { Fomentar el desarrollo de actividades comunitarias libres de tabaco, destacando el importante papel } \\
\text { de la ciudadanía y su necesario apoyo. }\end{array}$ \\
\hline $\begin{array}{l}\text { Propiciar la celebración del Día Mundial Sin Tabaco, como una manifestación social mayoritariamen- } \\
\text { te compartida frente al tabaco. }\end{array}$ \\
\hline $\begin{array}{l}\text { Promover la participación activa de grupos sociales, sindicales y profesionales, en la creación de un } \\
\text { clima social donde la norma sea no fumar, haciendo especial énfasis en la colaboración con los medios } \\
\text { de comunicación social (TV, radio, prensa, etc.). }\end{array}$ \\
\hline $\begin{array}{l}\text { Convocar anualmente subvenciones a proyectos y actividades de prevención del tabaquismo sin áni- } \\
\text { mo de lucro, promovidos por colectivos de jóvenes y ONGs. }\end{array}$ \\
\hline \multicolumn{1}{c|}{ Estrategia Investigación Evaluación } \\
\hline $\begin{array}{l}\text { Establecer un sistema de información que permita evaluar las acciones informativas, de cambio de ac- } \\
\text { titudes, de percepción del riesgo, de cumplimiento de las normas, y de tramitación y resolución de las } \\
\text { denuncias. }\end{array}$ \\
\hline
\end{tabular}

\section{Objetivo General 3:Potenciar la coordinación y la participación}

En el plazo de tres meses, tras la aprobación del Plan, se constituirá la Comisión Intersectorial de Dirección, que se reunirá con una periodicidad al menos anual, durante el quinquenio 2003-2007

\section{Objetivos Específicos:}

\subsection{Coordinación Institucional}

El Comité Ejecutivo del Plan Nacional elaborará las memorias anuales del periodo 2003-2007, presentando un informe global del quinquenio y las líneas de continuidad para el siguiente Plan, al finalizar el año 2007.

\subsection{Coordinación Intersectorial}

Antes de finalizar el año 2003, todas las Comunidades y Ciudades Autónomas deberán contar con un Plan de Prevención y Control del Tabaquismo.

\subsection{Coordinación Internacional}

El Plan estará representado en foros internacionales de control del tabaquismo, en el plazo de un año a partir de la aprobación del Plan.

\subsection{Participación Social}

Al menos el $1 \%$ del presupuesto global del Plan, se destinará anualmente a incentivar la participación social. 


\section{Actuaciones y estrategias para lograr el Objetivo Específico 3.1.- Coordinación} Institucional

\begin{tabular}{|c|}
\hline Estrategia Informativa \\
\hline $\begin{array}{l}\text { Garantizar una permanente información de la política de prevención y control del tabaquismo en Es- } \\
\text { paña. }\end{array}$ \\
\hline $\begin{array}{l}\text { Disponer de la información en su conjunto del desarrollo del Plan Nacional y de las actuaciones reali- } \\
\text { zadas en las Comunidades y Ciudades Autónomas. }\end{array}$ \\
\hline $\begin{array}{l}\text { Facilitar la información de las políticas internacionales en esta materia, desde los organismos respon- } \\
\text { sables a los órganos del Plan Nacional. }\end{array}$ \\
\hline $\begin{array}{l}\text { Realizar informes periódicos por la Secretaría del Plan Nacional sobre el estado de situación y desa- } \\
\text { rrollo del Plan Nacional. }\end{array}$ \\
\hline $\begin{array}{l}\text { Mantener actualizada la información por los Coordinadores Autonómicos de las actuaciones proce- } \\
\text { dentes de sus respectivos ámbitos territoriales. }\end{array}$ \\
\hline Estrategia Legislativa \\
\hline $\begin{array}{l}\text { Dotar al Plan Nacional de Prevención y Control del Tabaquismo del soporte jurídico oficial necesario } \\
\text { y de la asignación de recursos humanos y materiales, para la consecución de sus fines, garantizando el } \\
\text { funcionamiento de sus estructuras y organización. }\end{array}$ \\
\hline Promover la armonización en el conjunto del Estado de la normativa existente sobre tabaco. \\
\hline $\begin{array}{l}\text { Garantizar el seguimiento y cumplimiento de la normativa vigente, potenciando un sistema ágil y efi- } \\
\text { caz en los procedimientos de inspección, control, y sanción. }\end{array}$ \\
\hline Estrategia Coordinación Participación \\
\hline $\begin{array}{l}\text { Afianzar el liderazgo de la Administración Sanitaria dentro del conjunto de las Administraciones Pú- } \\
\text { blicas, en la prevención y control del tabaquismo. }\end{array}$ \\
\hline $\begin{array}{l}\text { Desarrollar como principio fundamental del Plan Nacional, la coordinación e integración de todas las } \\
\text { acciones dentro de este marco general de actuación. }\end{array}$ \\
\hline $\begin{array}{l}\text { Establecer la coordinación con el Plan Nacional sobre Drogas y sus correspondientes Planes Autonó- } \\
\text { micos, estableciendo canales de diálogo permanentes con otros Departamentos y entidades de ámbito } \\
\text { nacional, implicados en la prevención y control del tabaquismo. }\end{array}$ \\
\hline $\begin{array}{l}\text { Garantizar el intercambio de información y experiencias, manteniendo un contacto directo y perma- } \\
\text { nente entre la Secretaría del Plan y los Coordinadores Autonómicos. }\end{array}$ \\
\hline $\begin{array}{l}\text { Establecer los sistemas de información y los mecanismos de coordinación con los Planes Autonómi- } \\
\text { cos de Prevención y Control del Tabaquismo. }\end{array}$ \\
\hline $\begin{array}{l}\text { Contemplar los distintos niveles de desarrollo de las políticas de prevención y control del tabaquismo } \\
\text { en los respectivos ámbitos geográficos, potenciando aquellas con menor nivel de desarrollo. }\end{array}$ \\
\hline $\begin{array}{l}\text { Incrementar la coordinación con otras administraciones públicas, como Diputaciones, Ayuntamientos, } \\
\text { Cabildos, etc. }\end{array}$ \\
\hline Investigación Evaluación \\
\hline sistema de información que $p$ \\
\hline
\end{tabular}




\section{Actuaciones y estrategias para lograr el Objetivo Específico 3.2.- Coordinación} Intersectorial

\begin{tabular}{|l|}
\hline \multicolumn{1}{|c|}{ Estrategia Informativa } \\
\hline $\begin{array}{l}\text { Realizar una amplia difusión del Plan Nacional, que permita dar a conocer sus objetivos y actuaciones } \\
\text { a todos los sectores de la sociedad, tanto a nivel nacional como autonómico y local. }\end{array}$ \\
\hline $\begin{array}{l}\text { Canalizar y difundir la información nacional e internacional sobre políticas de tabaquismo, programas } \\
\text { de formación, ayudas y proyectos de investigación, fomentando la participación en los mismos. }\end{array}$ \\
\hline \multicolumn{1}{|c|}{ Estrategia Legislativa } \\
\hline $\begin{array}{l}\text { Buscar la colaboración y apoyo en el cumplimiento de la legislación vigente, y en la elaboración de } \\
\text { nuevas propuestas. }\end{array}$ \\
\hline \multicolumn{1}{|c|}{ Estrategia Coordinación Participación } \\
\hline $\begin{array}{l}\text { Intensificar la colaboración de los colectivos profesionales, sociedades científicas, asociaciones y or- } \\
\text { ganizaciones sociales, potenciando las actividades desarrolladas en materia de prevención del taba- } \\
\text { quismo. }\end{array}$ \\
\hline $\begin{array}{l}\text { Canalizar en los respectivos ámbitos autonómicos la coordinación con otros organismos y entidades } \\
\text { competentes en este tema. }\end{array}$ \\
\hline $\begin{array}{l}\text { Facilitar la colaboración de las diversas instituciones y entidades interesadas en la prevención y con- } \\
\text { trol del tabaquismo (Federación Española de Municipios y Provincias, de Consumidores y Usuarios, } \\
\text { de Madres y Padres, etc.). }\end{array}$ \\
\hline $\begin{array}{l}\text { Garantizar la participación de los distintos sectores implicados en la prevención y control del taba- } \\
\text { quismo, en las estructuras previstas en el Plan Nacional. }\end{array}$ \\
\hline $\begin{array}{l}\text { Establecer canales de diálogo permanentes con otros Departamentos y entidades implicados en la pre- } \\
\text { vención y control del tabaquismo, a través de los mecanismos previstos en el Plan Nacional. }\end{array}$ \\
\hline $\begin{array}{l}\text { Impulsar, con el patrocinio del Plan Nacional, la celebración de un encuentro anual en el que partici- } \\
\text { pen las entidades, asociaciones científicas, profesionales y ciudadanas y las Administraciones Públi- } \\
\text { cas, interesados en la prevención y control del tabaquismo. }\end{array}$ \\
\hline \begin{tabular}{l} 
Potenciar la celebración del Día Mundial Sin Tabaco, planificando actuaciones coordinadamente. \\
\hline Establecer un sistema de información que permita evaluar las actuaciones y estrategias.
\end{tabular} \\
\hline
\end{tabular}




\section{Actuaciones y estrategias para lograr el Objetivo Específico 3.3.- Coordinación} Internacional

\begin{tabular}{|l|}
\hline \multicolumn{1}{|c|}{ Estrategia Informativa } \\
\hline $\begin{array}{l}\text { Facilitar información del Plan Nacional y el desarrollo de sus objetivos y actuaciones a los organismos } \\
\text { internacionales. }\end{array}$ \\
\hline Participar en los foros informativos internacionales relacionados con esta materia. \\
\hline \multicolumn{1}{c|}{ Estrategia Legislativa } \\
\hline $\begin{array}{l}\text { Colaborar con el Grupo de Salud del Consejo de la Unión Europea para la elaboración de la Directi- } \\
\text { vas Comunitarias. }\end{array}$ \\
\hline $\begin{array}{l}\text { Participar y apoyar las orientaciones legislativas de la Organización Mundial de la Salud y de la Unión } \\
\text { Europea. }\end{array}$ \\
\hline $\begin{array}{l}\text { Contemplar como marco referencial, la Estrategia Europea para el Control del Tabaquismo de la Or- } \\
\text { ganización Mundial de la Salud. }\end{array}$ \\
\hline Apoyar al Convenio Marco para el Control del Tabaco de la Organización Mundial de la Salud. \\
\hline Participar en los foros internacionales de prevención y control del tabaquismo. \\
\hline $\begin{array}{l}\text { Apoyar y promover las estrategias de la Organización Mundial de la Salud en la prevención y control } \\
\text { del tabaquismo. }\end{array}$ \\
\hline $\begin{array}{l}\text { Canalizar y difundir la información de proyectos y programas internacionales de investigación e in- } \\
\text { tervención en la prevención y control del tabaquismo, fomentando la participación en los mismos. }\end{array}$ \\
\hline $\begin{array}{l}\text { Divulgar la información de programas de formación sobre tabaco y salud, programas de intercambio } \\
\text { y de ayudas, etc. }\end{array}$ \\
\hline $\begin{array}{l}\text { Participar en la celebración del Día Mundial Sin Tabaco, desarrollando las estrategias señaladas por la } \\
\text { Organización Mundial de la Salud. }\end{array}$ \\
\hline \multicolumn{1}{c|}{ Estrategia Investigación Evaluación } \\
\hline Establecer un sistema de información que permita evaluar estas actuaciones. \\
\hline
\end{tabular}




\section{Actuaciones y estrategias para lograr el Objetivo Específico 3.4.- Participación} Social

\begin{tabular}{|l|}
\hline \multicolumn{1}{|c|}{ Estrategia Informativa } \\
\hline $\begin{array}{l}\text { Difundir ampliamente la información del Plan Nacional a todos los sectores de la sociedad, tanto a ni- } \\
\text { vel nacional como autonómico y local. }\end{array}$ \\
\hline $\begin{array}{l}\text { Informar de la necesidad, oportunidad y mecanismos de participación en el desarrollo del Plan Nacio- } \\
\text { nal. }\end{array}$ \\
\hline $\begin{array}{l}\text { Llamar la atención de la población, informando periódicamente sobre los problemas ocasionados por } \\
\text { el tabaquismo voluntario e involuntario. }\end{array}$ \\
\hline \multicolumn{1}{c|}{ Estrategia Educativa Formativa } \\
\hline $\begin{array}{l}\text { Fomentar actuaciones que estimulen la conducta de no fumar como norma social, promoviendo el } \\
\text { concepto de sociedades libres de tabaco. }\end{array}$ \\
\hline $\begin{array}{l}\text { Estimular el sentido crítico de la población, tomando en cuenta las estrategias y presiones existentes } \\
\text { para consumir tabaco. }\end{array}$ \\
\hline $\begin{array}{l}\text { Realizar campañas formativas dirigidas a población general y colectivos específicos, concienciando } \\
\text { sobre los daños ocasionados por el consumo de tabaco y la necesidad de colaborar en el cumplimien- } \\
\text { to de la legislación vigente. }\end{array}$ \\
\hline \multicolumn{1}{c|}{ Estrategia Legislativa } \\
\hline $\begin{array}{l}\text { Exponer las medidas legislativas y sus objetivos como instrumentos necesarios de protección de la sa- } \\
\text { lud. }\end{array}$ \\
\hline Buscar el apoyo en el cumplimiento de la normativa vigente. \\
\hline $\begin{array}{l}\text { Elaborar y distribuir materiales de apoyo sobre la legislación y los mecanismos para hacer eficaz su } \\
\text { cumplimiento. }\end{array}$ \\
\hline \multicolumn{1}{c|}{ Estrategia Coordinación Participación } \\
\hline $\begin{array}{l}\text { Incentivar el movimiento ciudadano y asociativo interesado en la prevención y control del tabaquis- } \\
\text { mo, apoyando sus actividades y fomentando la creación de nuevas organizaciones. }\end{array}$ \\
\hline $\begin{array}{l}\text { Facilitar la participación de organizaciones sociales, sindicales y de consumidores relacionadas con } \\
\text { esta materia. }\end{array}$ \\
\hline Incentivar programas formativos y actividades promovidos por colectivos sociales. \\
\hline $\begin{array}{l}\text { Promover la participación y el compromiso de autoridades, personalidades y otros líderes sociales, en } \\
\text { las actuaciones de prevención y control del tabaquismo. }\end{array}$ \\
\hline Establecer un sistema de información que permita evaluar estas actuaciones. \\
\hline
\end{tabular}




\section{ESTRUCTURA, FUNCIONES Y RECURSOS}

El Plan Nacional de Prevención y Control del Tabaquismo dependerá orgánica y funcionalmente del Ministerio de Sanidad y Consumo, y contará con una Comisión Intersectorial de Dirección y un Comité Ejecutivo. Este último integrado por el/la Coordinador/a General, la Secretaría Permanente y los/las Coordinadores/as Autonómicos.

\section{Comisión Intersectorial de Dirección}

Composición

- Titular del Ministerio de Sanidad y Consumo, que actuará de Presidente/a.

- Dos representantes del Pleno del Consejo Interterritorial del SNS.

- Director/a General de Salud Pública del Ministerio de Sanidad y Consumo.

- Dos representantes de la Comisión de Salud Pública del Consejo Interterritorial del SNS.

- Coordinador/a General del Plan Nacional (PNPyCT).

- Un representante de cada uno de los Departamentos de Educación Cultura y Deporte, Trabajo y Asuntos Sociales, Economía, Hacienda e Interior.

- Un representante del Comité Nacional para la Prevención del Tabaquismo.

- Un representante de la Secretaría Permanente del Plan Nacional (PNPyCT) (con voz y sin voto).

\section{Funciones}

Actuará como órgano de carácter colegiado, se reunirá al menos una vez al año y tendrá las siguientes funciones:
1. Ser el foro de encuentro de los distintos sectores interesados en la prevención y control del tabaquismo en España, para el consenso de las actuaciones en esta materia.

2. Establecer el seguimiento y desarrollo del Plan.

3. Establecer la coordinación de las actuaciones de los distintos sectores representados, canalizando la participación comunitaria.

4. Asegurar la financiación adecuada y distribución de los recursos para el desarrollo del Plan Nacional de Prevención y Control del Tabaquismo.

\section{Comité Ejecutivo}

Estará formado por el/la Coordinador/a General del Plan, los/as Coordinadores/as Autonómicos y la Secretaría Permanente y tendrá las siguientes funciones:

1. Establecer las prioridades del Plan y las propuestas de líneas de actuación.

2. Elaboración de los presupuestos, acordando los criterios de distribución de los mismos entre los distintos órganos del Plan asegurando que los fondos asignados se destinan a las prioridades establecidas.

3. Realizar el seguimiento de las actuaciones acordadas.

4. Elaboración de los informes y memorias anuales de actividades tomando como referencia los informes y memorias realizadas en las respectivas Comunidades y Ciudades Autónomas.

5. Establecer los sistemas de información y evaluación del Plan Nacional de Prevención y Control del Tabaquismo.

Rev Esp Salud Pública 2003, Vol. 77, N. ${ }^{\circ} 4$ 


\subsection{Coordinador/a General del Plan}

Adscrito a la Subdirección General de Promoción de la Salud y Epidemiología de la Dirección General de Salud Pública del Ministerio de Sanidad y Consumo, con dedicación exclusiva, tendrá las siguientes funciones:

1. Actuar de Secretario Ejecutivo del Plan.

2. Presentar propuestas para el desarrollo de las estrategias recogidas en el Plan Nacional de Prevención y Control del Tabaquismo.

3. Velar por el cumplimiento de los acuerdos.

4. Presentar a la Comisión Intersectorial de Dirección los presupuestos y los criterios de distribución de los mismos entre los distintos órganos del Plan.

5. Localizar y recabar financiación de otros organismos nacionales e internacionales.

6. Dinamizar los órganos de coordinación y las actuaciones del Plan.

7. Ostentar la representación del Plan Nacional de Prevención y Control del Tabaquismo en los foros técnicos nacionales e internacionales.

8. Difundir la información generada en esta materia.

\subsection{Coordinadores/as Autonómicos}

Cada Comunidad y Ciudad Autónoma dispondrá de un técnico de referencia como coordinador/a del Plan Nacional en su ámbito territorial, que formará parte del Comité Ejecutivo y tendrá las funciones asignadas al mismo.

\subsection{Secretaría Permanente}

Dependerá de la Subdirección General de Promoción de la Salud y Epidemiología, de la Dirección General de Salud Pública. Estará dirigida por el/la Coordinador/a General del Plan, y formada, al menos, por tres técnicos (jefes de servicio) de la Subdirección General de Promoción de la Salud y Epidemiología, y tres administrativos.

Sus funciones serán:

1. Dar soporte técnico al Coordinador/a.

2. Participar en la Comisión Intersectorial de Dirección.

3. Mantener la comunicación permanente y elaborar propuestas en colaboración con la red de coordinadores técnicos de las Comunidades y Ciudades Autónomas.

4. Participar en los grupos de trabajo que se creen en el seno del Comité Ejecutivo.

5. Elaborar informes periódicos y la memoria anual de actividades.

6. Aplicar progresivamente los mecanismos de evaluación recogidos en el Plan.

\section{Asesorías técnicas}

El Plan Nacional de Prevención y Control del Tabaquismo, a través de su Secretaría Permanente, podrá recabar cuando estime oportuno, el asesoramiento técnico de expertos en las diferentes materias relacionadas con el tabaquismo.

Inicialmente, durante el periodo de implantación del Plan, el Grupo de Trabajo de Tabaco (Ponencia de Promoción de la Salud de la Comisión de Salud Pública del Consejo Interterritorial del SNS, constituido por técnicos de las Comunidades Autónomas de Andalucía, Aragón, Canarias, Extremadura, Galicia, Navarra, Valencia, y de la Subdirección General de Promoción de la Salud y Epidemiología del MSC), continuará su función técnica y asesora. 


\section{Recursos económicos}

La Administración General del Estado aportará para su estructura y funcionamiento, el equivalente a un porcentaje de lo recaudado por los impuestos especiales de los productos de tabaco, que anualmente determinará la Comisión Intersectorial de Dirección, en función de las actuaciones que se programen para cada año de vigencia del Plan Nacional.

Para el primer año, el Ministerio de Sanidad y Consumo aportará 3,6 millones de euros.
Cada CCAA y CA deberá contar con un presupuesto finalista, dedicado a la prevención y control del tabaquismo, equivalente al menos a 0.25 euros per capita y año.

La aplicación del Plan Nacional de Prevención y Control del Tabaquismo está condicionada a la existencia en cada CCAA y CA de un Plan Autonómico por lo que éstas, deberán además dotar a sus respectivos territorios de los recursos humanos y financieros necesarios. Como mínimo se deberá contar con un/a Coordinador/a Autonómico y un técnico de referencia por área de salud u otra demarcación geográfica en función de la realidad de cada Comunidad o Ciudad Autónoma.

\section{PLAN NACIONAL DE PREVENCIÓN Y CONTROL DEL TABAQUISMO}

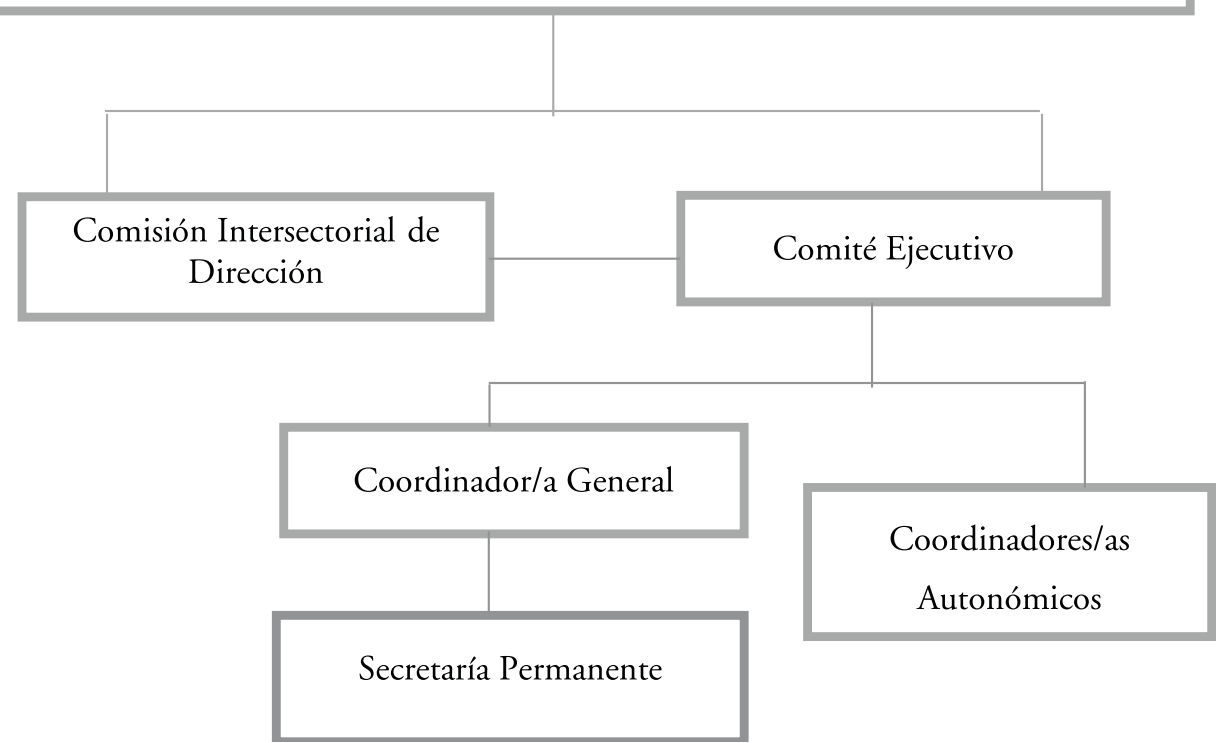

\section{EVALUACIÓN}

\section{Sistema de información y evaluación}

La evaluación del Plan Nacional de Prevención y Control de Tabaquismo 2003-
2007 constituirá una valoración de la puesta en marcha del Plan y su pertinencia, estimando necesaria una aplicación progresiva de los mecanismos de evaluación. Dada la imposibilidad de actuación simultánea e inmediata de todas las intervenciones estratégicas defi- 
nidas por el Plan, los flujos, frecuencia, tipos de información y otros indicadores se irán estableciendo a medida que se progrese en el desarrollo del Plan, ya que estamos hablando de un proceso que consume tiempo, dedicación a la organización, desarrollo y gestión.

Anualmente la Secretaría Permanente y los Coordinadores Autonómicos del Plan realizarán una evaluación que contemplará:

- Estructura del Plan; órganos de coordinación y su funcionamiento, recursos humanos (RRHH) y materiales (RRMM), desarrollo presupuestario y aquellos elementos que favorecen o condicionan la continuidad de la estructura del Plan.

- Proceso: planificación y desarrollo de las estrategias básicas y de las actividades del Plan para la consecución de los objetivos operativos.

- Resultados: que permitan contemplar el grado de cumplimiento de los objetivos generales y específicos establecidos en el Plan.

Se realizará una evaluación externa del Plan en dos tiempos:

1. Al finalizar el segundo año de la puesta en marcha del Plan, esta evaluación contemplará el diseño del Plan y la formalización y funcionamiento de los órganos de coordinación.

2. Al finalizar el Plan se evaluará, además de los ámbitos descritos en el punto anterior, el nivel de consecución de los objetivos generales y específicos.

Para el desarrollo de la evaluación del Plan se contará con una dotación presupuestaria específica.

La Secretaría Permanente y los/as Coordinadores/as Autonómicos del Plan elaborarán la memoria anual que contemplará el grado de cumplimiento alcanzado de los objetivos previstos y el grado de ejecución presupuestaria. Esta memoria se presentará a la Comisión Intersectorial de Dirección, para su elevación al Pleno del Consejo Interterritorial del SNS.

\section{Indicadores de estructura}

En el primer trimestre de 2003 se habrá publicado la norma que regule la creación, composición y funciones de los órganos de coordinación y participación así como los medios de financiación del Plan Nacional de Prevención y Control del Tabaquismo.

En el plazo de tres meses tras la aprobación del Plan, se habrán constituido los órganos de coordinación previstos en el Plan Nacional de Prevención y Control del Tabaquismo y todas las Comunidades y Ciudades Autónomas dispondrán, además del técnico responsable en materia de tabaco (Coordinador/a Autonómico), de al menos un técnico de referencia por el ámbito territorial que se determine, para el desarrollo de las actuaciones que se prioricen desde el Plan Nacional de Prevención y Control del Tabaquismo.

\section{Indicadores de proceso}

Se determinarán en función a las actuaciones que se prioricen anualmente condicionadas por los recursos asignados.

\section{Indicadores de resultados}

Incluir fuentes de información que se utilizarán como referencia (ENS, EDIS, Encuesta en escolares de 14 a 18 años PND).

\section{Prevalencia}

- \% de fumadores por género y grupos de edad. (FD +FO)

Número de fumadores / número de personas $\geq 16$ años 
- \% de fumadores habituales por género y grupos de edad. (FD)

- \% de fumadores ocasionales por género y grupos de edad. (FO)

- \% de ex fumadores por género y grupos de edad. (EF)

- \% de nunca fumadores por género y grupos de edad. (NF)

- \%s en población menor de 16 años por género.

- \% de abandono. EF/(FD+FO+EF)

- Edad de inicio: Edad media de inicio del consumo de tabaco por género y grupo de edad (experimentación primer cigarrillo / consumo diario).

\section{Mortalidad}

- Tasa de mortalidad atribuible al consumo de tabaco global, por género y grupo de edad.

- Tasa de mortalidad atribuible al consumo de tabaco por enfermedades y género y grupo de edad.

\section{Morbilidad}

- Número de consultas especializadas por diferentes patologías.

\section{Centros sanitarios}

- \% de $\mathrm{H}^{\mathrm{a}}$ clínicas que recogen el hábito tabáquico.
- \% de $\mathrm{H}^{\mathrm{a}}$ clínicas que recogen la aplicación del consejo/intervención mínima.

- \% de Hospitales acreditados como Hospital sin tabaco. Categoría bronce.

- \% de Hospitales acreditados como Hospital sin tabaco. Categoría plata.

- \% de Hospitales acreditados como Hospital sin tabaco. Categoría oro.

- Número de unidades de deshabituación tabáquica.

5. Profesionales Sanitarios (personal médico, de enfermería y farmacéutico)

- \% de profesionales sanitarios que FD por grupo de edad y género.

- \% de profesionales sanitarios que FO por grupo de edad y género.

- \% de profesionales sanitarios que EF por grupo de edad y género.

- \% de profesionales sanitarios que NF por grupo de edad y género.

\section{Espacios sin humo}

- \% de centros sanitarios.

- \% de centros docentes.

- \% de centros administrativos.

- \% de empresas sin humo 


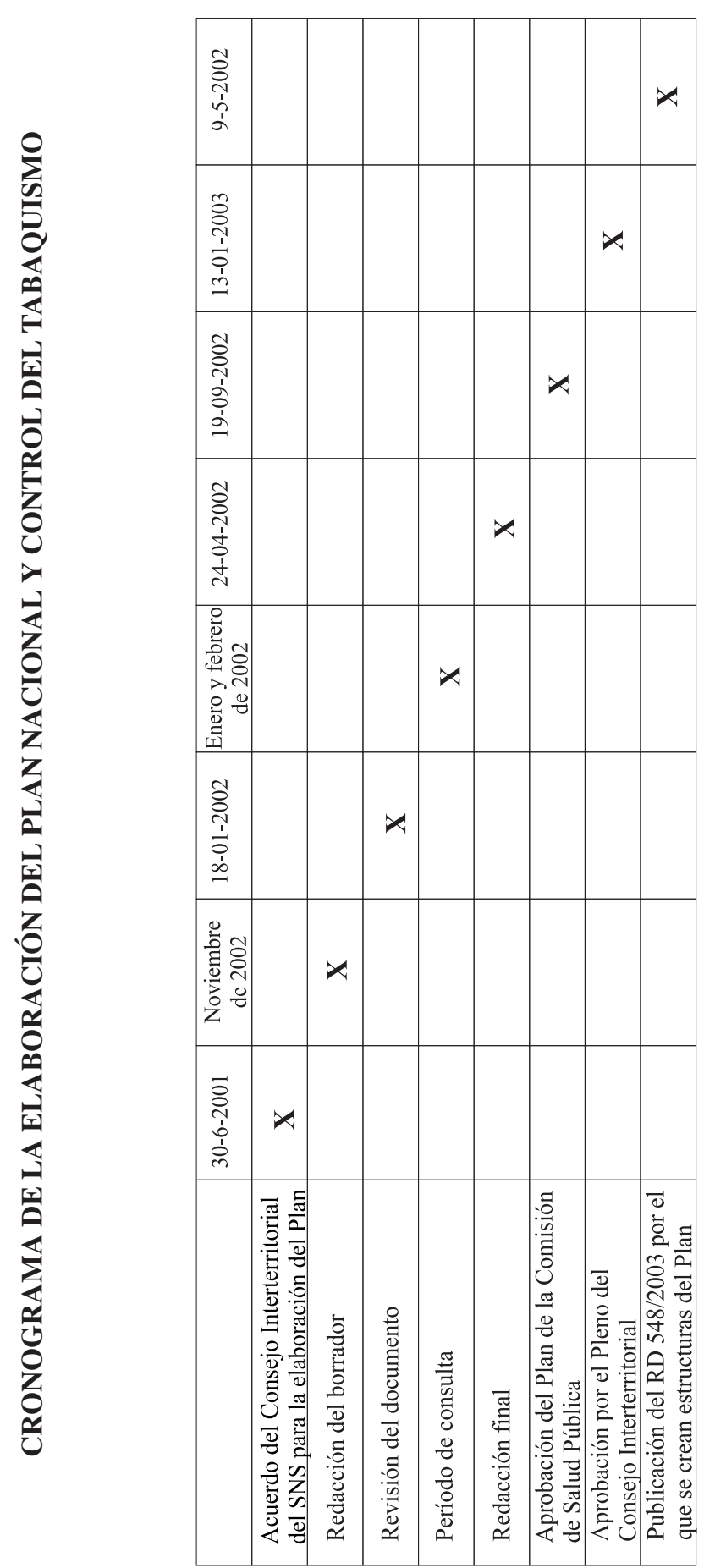

Rev Esp Salud Pública 2003, Vol. 77, N. ${ }^{\circ} 4$ 